Canadian

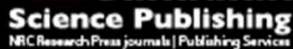

Canadian Geotechnical Journal Revue canadienne de géotechnique

\title{
An analysis of passive earth pressure modification due to seepage flow effects
}

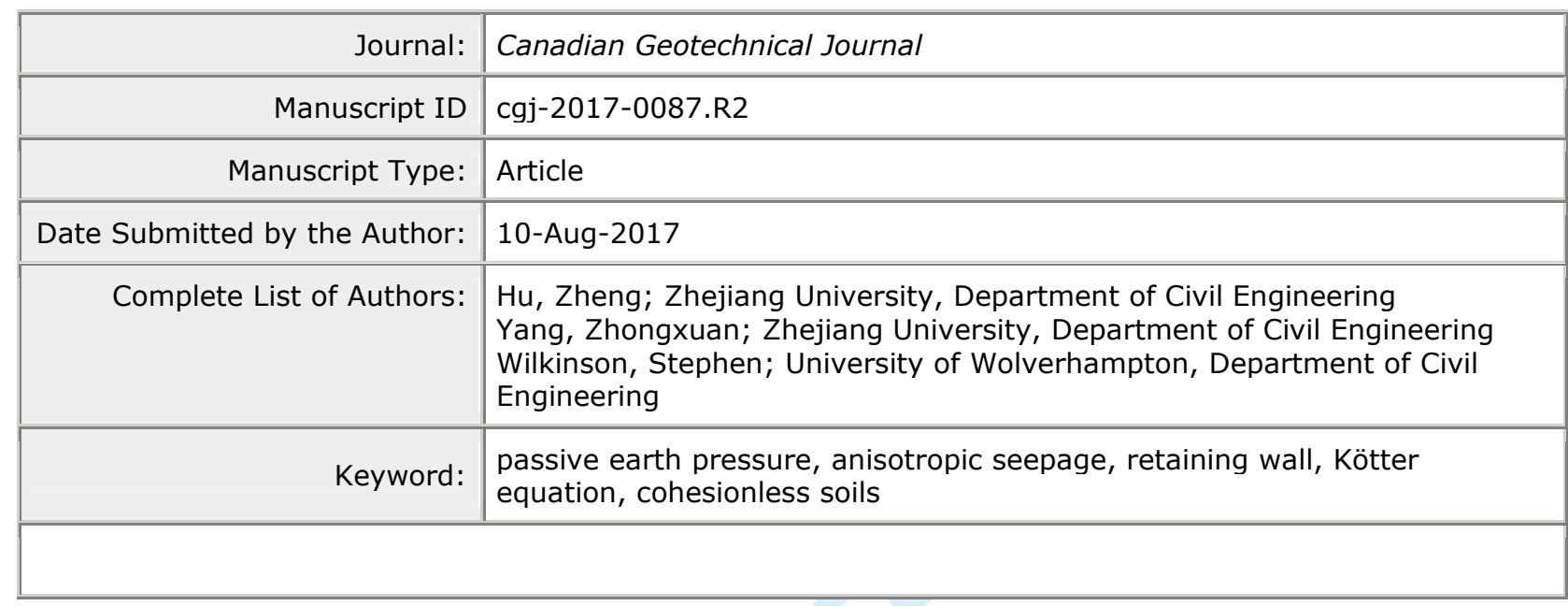




\section{Title Page}

\section{(i) Title}

An analysis of passive earth pressure modification due to seepage flow effects

\section{(ii) Authors}

Z. $\mathrm{HU}^{1}$, Z.X. YANG ${ }^{2 *}$, S.P. WILKINSON ${ }^{3}$

\section{(iii) Affiliation and address}

${ }^{1}$ Ph.D. student, Department of Civil Engineering, Zhejiang University, 866 Yuhangtang

Road, Hangzhou, China, Email: huzheng@zju.edu.cn

${ }^{2}$ Professor, Department of Civil Engineering, Zhejiang University, 866 Yuhangtang

Road, Hangzhou, China, Email: zxyang@zju.edu.cn

${ }^{3}$ Senior Lecturer, Department of Civil Engineering, University of Wolverhampton,

Wulfruna Street WV1 1LY, U.K., Email: S.Wilkinson4@wlv.ac.uk

* Corresponding author

\section{(iv) Corresponding author}

Name: Z.X. Yang

Address: Room B712 Anzhong Building, Zhejiang University, Zijingang Campus, 866 Yuhangtang Road, Hangzhou, China

Telephone number: +8613136161267

Fax number: +86 57188208476

E-mail: zxyang@zju.edu.cn 


\title{
An analysis of passive earth pressure modification due to seepage flow effects
}

\author{
Z. $\mathrm{Hu}^{1}$, Z.X. Yang ${ }^{2 *}$, S.P. Wilkinson ${ }^{3}$
}

Abstract

Using an assumed vertical retaining wall with a drainage system along the soil-structure interface, this paper analyses the effect of anisotropic seepage flow on the development of passive earth pressure. Extremely unfavourable seepage flow inside the backfill, perhaps due to heavy rainfall, will dramatically increase the active earth pressure while reducing the passive earth pressure; thus increasing the probability of instability of the retaining structure. In this paper, a trial and error analysis based on limit equilibrium is applied to identify the optimum failure surface. The flow field is computed using Fourier series expansion, and the effective reaction force along the curved failure surface is obtained by solving a modified Kötter equation considering the effect of seepage flow. This approach correlates well with other existing results. For small values of both the internal friction angle and the interface friction angle, the failure surface can be appropriately simplified with a planar approximation. A parametric study indicates that the degree of anisotropic seepage flow affects the resulting passive earth pressure. In addition, incremental increases in the effective friction angle and interface friction both lead to an increase in the passive earth pressure.

Keywords: passive earth pressure; anisotropic seepage; retaining wall; Kötter equation; cohesionless soils

\footnotetext{
${ }^{1}$ Ph.D. student, Department of Civil Engineering, Zhejiang University, Hangzhou, China, email: huzheng@zju.edu.cn

2 Professor, Department of Civil Engineering, Zhejiang University, Hangzhou, China, email: zxyang@zju.edu.cn

${ }^{3}$ Senior Lecturer, Department of Civil Engineering, University of Wolverhampton, UK, email: S.Wilkinson4@wlv.ac.uk

* Corresponding Author
} 


\section{Introduction}

Earth pressure is one of the oldest and most classical problems in geotechnical design and has been extensively studied and reported in the literature. In practical engineering, the most famous methods for calculating earth pressures are the Coulomb (1776) and Rankine (1867) earth pressure theories, which can be categorised as limit equilibrium methods; these approaches have been more recently developed considering the movement modes of retaining structures (Sabzevari and Ghahramani 1973), surcharge loading (Motta 1994) and seismic effects (Ghosh 2008; Ghosh and Sharma 2012). Other major approaches to the calculation of earth pressures include the limit analysis method (Collins 1973; Soubra and Macuh 2002; Yang 2007), slip line method (Chen and Li 1998; Cheng 2003; Liu and Wang 2008), and the method of characteristics (Sokolovskii 1965; Kumar 2001; Kumar and Chitikela 2002). These methods provide alternative approaches to calculating the earth pressures of the backfill behind retaining structures under varying conditions.

The classical theories such as Coulomb's theory of earth pressure use a failure surface which is normally assumed to be planar. However, it has long been recognized that the real failure surface in the backfill may consist of a curved lower section and a straight upper section, due to the influence of the soil-wall interface friction (Terzaghi 1941; Bishop 1966; Fang and Ishibashi 1986; Terzaghi et al. 1996). To assess this mixed failure surface shape, a log-spiral failure surface was proposed by Morrison and Ebeling (1995) allowing the calculation of the passive earth pressure using the limit equilibrium method. Since then, various methods adopting curved 
failure surfaces have been developed including considering more general ground and loading conditions. For example in recent years, surcharge loading (Soubra 2000; Škrabl and Macuh 2005), cohesive-frictional backfill (Subba Rao and Choudhury 2005; Xu et al. 2015), and seismic effects (Kumar 2001; Brandenberg et al. 2015) have been incorporated. By comparing the experimental data and calculated results, Fang et al. (2002) found that the curved failure surface is superior to the planar surface in the passive mode. Therefore, a log-spiral failure surface is employed to calculate the passive earth pressure acting on a rigid retaining wall in the present study.

Seepage flow is also a key factor influencing the pore pressure and effective stress distribution within the backfill, and thus affecting the earth pressure acting on retaining structures, which has been extensively investigated (Harr 1962; Siddiqua et al. 2013; Veiskarami and Zanj 2014). The governing equation for seepage flow can be simplified as a two-dimensional Laplace equation with prescribed boundary conditions. Given the difficulties in solving the equation analytically, numerical methods such as the finite difference method (Soubra et al. 1999; Benmebarek et al. 2006), finite element method (Wang and Cheung 2001; Helwany 2007), and boundary element method (Barros and Santos 2012; Ai and Hu 2015) are normally employed. In these studies, the active earth pressure increases and the passive earth pressure reduces with the presence of the seepage flow, reducing the bearing capacity of the retaining wall significantly and increasing the potential for severe damage, economic losses and environmental harm (Budhu 2011; Siddiqua et al. 2011). Through model tests, Ichihara et al. (1982) quantified the effect of seepage 
flow on the earth pressure distribution and found that seepage flow can increase the active earth pressure by as much as $64 \%$ in comparison to the no flow scenario. However, at present no such experiments have been presented to assess the effect of seepage flow on passive earth pressures.

Where seepage flow is accounted for in the calculation of earth pressure, for simplicity isotropic flow conditions are commonly assumed. By assuming planar failure surfaces, the effect of seepage flow on the active earth pressure of a rigid retaining wall has been investigated using limit equilibrium methods; see Barros (2006), Wang et al. (2008a, b) and Santos and Barros (2015). However, such solutions cannot be extended to the passive case due to difficulties in calculating the reaction forces along the curved failure surface under seepage flow conditions. In addition, it has long been recognized that seepage flow is commonly not isotropic but anisotropic, as most retaining structure backfills display some degree of anisotropy due to their deposition and compaction process and the normal stress conditions, thus the coefficients of the permeability normally vary in the horizontal and vertical directions (Jeng et al. 2001; Ai and Wu 2009; Rafiezadeh and Ashtiani 2014). Field measurements have shown that permeability values in the horizontal direction are multiples of those in the vertical direction; this can significantly affect the pore pressure distribution in the backfill behind the wall (Kenney 1963; Head 1988; Jeng et al. 2001; Hazelton and Murphy 2007). By assuming that the horizontal axis coincides with the direction of the maximum permeability, Hu et al. (2017) showed analytically that the anisotropic permeability of the backfill can significantly affect 
the distribution of both the pore water pressure and the active earth pressure on retaining structures. However, studies of the passive earth pressure including anisotropic seepage flow are rarely considered and thus this aspect requires further investigation.

The present paper proposes a method for calculation of the passive earth pressure accounting for anisotropic seepage flow inside the backfill, based on an analytical solution of anisotropic seepage flow using Fourier series expansion. A complete log-spiral surface mimicking the passive failure is assumed in the analysis, and a modified Kötter (1903) equation considering anisotropic seepage effect is primarily employed to calculate the effective resultant earth reaction distribution on the curved failure surface. The proposed method has the following important main features: a) a trial and error approach is used to determine the unique passive thrust, without requiring a pre-assumed location of the earth thrust in force equilibrium analysis; b) the anisotropic seepage is included such that the effect of groundwater flow inside the backfill can be accurately evaluated; c) the effective soil reaction force along the failure surface is calculated using a modified Kötter equation considering the effect of anisotropic seepage flow, ensuring that both the force and moment equilibrium conditions can be applied and the location of the passive earth thrust can be determined. A comparison between calculated results and the results from other studies indicates that the anisotropic seepage flow affects the passive earth pressure, especially for the cases with larger internal friction angle and soil-wall interface friction angle. Parametric studies of the anisotropic coefficient of 
permeability, the internal friction angle of soils and the soil-wall interface friction angle are also presented to show their respective or joint influences on the coefficients of passive earth pressure. Finally, a simplified version of the proposed procedure is also put forward, in which a planar failure surface is considered. This provides a good approximation in comparison with those using curved failure surface methods given a small internal friction angle of the soil and a small soil-wall interface friction angle. Thus under such conditions the simplified method can be applied to calculate the passive earth pressure including the effects of anisotropic seepage flow.

\section{Outline of the Analysis}

\section{Assumptions}

The analysis presented in this paper considers the case of a vertical rigid retaining wall resting against a horizontal cohesionless backfill with anisotropic seepage flow, originating from a continuous source on the horizontal surface. An external strut force is pushing the wall to move towards the soil and the soil to behave passively. In addition, the rigid retaining wall is provided with a drainage system along the soil-wall interface and the layer beneath the wall. The horizontal surface at $y=0$ is an impervious layer. The resulting flow net under anisotropic seepage conditions is illustrated in Fig. 1.

In order to obtain the earth pressure solution given anisotropic seepage, the following assumptions are made:

1) The shape of the failure surface is taken as a complete log spiral, extending from 
the wall heel to the horizontal ground surface (Fig. 2).

2) The backfill is fully saturated and homogeneous, and the principal directions of permeability coincide with the horizontal and vertical directions;

3) The flow is in the steady laminar state and obeys the linear form of Darcy's law.

These assumptions have been widely used for the analysis of passive earth pressure on retaining walls, e.g. Morrison and Ebeling (1995), Soubra and Macuh (2002), and Patki et al. (2015a).

\section{Methodology}

According to the free-body diagram of the failure wedge illustrated in Fig. 2, the following forces are identified:

1) The passive thrust on the retaining wall $P_{\mathrm{p}}$, of which the horizontal and vertical components are $P_{\mathrm{h}}$ and $P_{\mathrm{v}}$, respectively.

2) The self-weight of the failure segment $A B C$ is $W$.

3) The effective resultant soil reaction force $R^{\prime}$ along the failure surface AC. Its horizontal and vertical components are designated as $R_{\mathrm{h}}{ }^{\prime}$ and $R_{\mathrm{v}}{ }^{\prime}$, respectively.

4) The resultant pore pressure force $U$, due to the seepage inside the backfill acting on the failure surface AC. Its horizontal and vertical components are designated as $U_{\mathrm{h}}$ and $U_{\mathrm{v}}$, respectively.

A trial and error procedure is performed to obtain the passive thrust $P_{\mathrm{p}}$, following the method shown in Fig. 3. Two parameters $\theta_{v}$ and $\theta_{c r}$ that determine the location of the pole of the log spiral and the geometry of the failure wedge are treated as unknowns in the iterative analysis. For any given values of the angle $\theta_{v}$ and $\theta_{c r}$, it is 
possible to determine a complete geometry of the failure wedge that is sensitive to the input parameters, including the effective friction angle $\varphi^{\prime}$, soil-wall interface friction angle $\delta$ and the wall height $H$. A modified Kötter equation considering the effect of seepage flow is applied to calculate the effective reaction force $R^{\prime}$ along the curved failure surface, and the pore water pressure force $U$ resulting from the seepage flow is obtained by solving the Laplace equation under the prescribed boundary conditions (Fig. 1). Details of the effective reaction force and the pore water pressure force will be presented towards the end of this paper.

The protocol proposed here involves the application of both horizontal and vertical limit-equilibrium conditions to determine the horizontal and vertical earth pressure components $P_{\mathrm{h}}$ and $P_{\mathrm{v}}$, and thus the passive earth thrust with $P_{\mathrm{p}}=P_{\mathrm{h}} / \cos \delta=P_{\mathrm{v}} / \sin \delta$. If the assumed values of $\theta_{\mathrm{v}}$ and $\theta_{\mathrm{cr}}$ are acceptable, then the obtained passive thrust $P_{\mathrm{p}}$ from both the horizontal and vertical directions must be equal or within a small error range. If this is not the case the values of the angle $\theta_{\mathrm{v}}$ and $\theta_{\mathrm{cr}}$ are modified, and the calculation procedure is repeated until the above convergence condition has been satisfied.

Several values of passive thrust that fulfill the above conditions can be obtained, with passive thrusts locations which can be obtained through back-calculation using the moment equilibrium condition with known values of $P_{\mathrm{p}}$. The criterion of $T / H=1 / 3$ is applied in order to identify the optimum value of $P_{\mathrm{p}}$. Therefore, the failure surface that yields the closest value to $T / H=1 / 3$ will be identified for the passive thrusts locations. The same approach has also been adopted by Barros (2006) and Patki et al. 
(2017).

\section{Anisotropic seepage solutions}

Total head $h(x, y)$

In the present study, seepage analysis is carried out primarily to determine the $2-D$ distribution of the total head $h(x, y)$. The mathematical model used to obtain the solutions to the anisotropic seepage through the saturated backfill is derived from the Laplace differential equation,

$$
k_{x} \frac{\partial^{2} h}{\partial x^{2}}+k_{y} \frac{\partial^{2} h}{\partial y^{2}}=0
$$

where $k_{\mathrm{x}}$ and $k_{\mathrm{y}}$ are coefficients of permeability in the horizontal and vertical directions respectively. For the case considered in Fig. 1, Barros (2006) obtained a solution to the Laplace equation for isotropic soil based on Fourier series expansion. To investigate the effect of the anisotropy of seepage flow, the ratio of permeability coefficient $\xi=\left(k_{\mathrm{y}} / k_{\mathrm{x}}\right)^{1 / 2}$ was introduced by $\mathrm{Hu}$ et al. (2017), and the solution to the Laplace equation for anisotropic seepage can be then obtained as

$$
h(x, y)=H\left[1-\sum_{m=0}^{\infty} \frac{2}{M^{2}} \mathrm{e}^{-\frac{M x \xi}{H}} \cos \frac{M y}{H}\right]
$$

where $m$ is number of term in Fourier series and $M$ is obtained by

$$
M=\frac{(2 m+1) \pi}{2}
$$

The pore pressure at any point inside the soil mass is

$$
u(x, y)=\gamma_{w}[h(x, y)-y]
$$

where $\gamma_{w}$ is the unit weight of water.

In order to obtain the pore water pressure acting on the curved failure surface, the 
total head $h(x, y)$ along the log-spiral failure surface can be expressed in a polar coordinate system, as shown in Fig. 4. The transformation equations between the $x-y$ Cartesian coordinate system and $r-\theta$ polar coordinates on the curved failure surface can be obtained by

$$
\left\{\begin{array}{l}
x=-r_{0} \sin \theta_{v}+r_{0} \mathrm{e}^{\theta \tan \varphi^{\prime}} \sin \left(\theta_{v}+\theta\right) \\
y=r_{0} \cos \theta_{v}-r_{0} \mathrm{e}^{\theta \tan \varphi^{\prime}} \cos \left(\theta_{v}+\theta\right)
\end{array}\right.
$$

where $\varphi^{\prime}$ is the effective internal friction angle of soils, $r_{0}$ is the initial radius of the log spiral, $\theta$ is the angle made by the intermediate radii of the log spiral with the initial radii.

Pore pressure along the curved failure surface

Based on the coordinate transformation rule given in Eq. (5), the total head along the failure surface can be obtained,

$$
h=H\left[1-\sum_{m=0}^{\infty} \frac{2}{M^{2}} \mathrm{e}^{-\frac{M \xi\left[-r_{0} \sin \theta_{v}+r_{0} e^{\tan \varphi^{\prime}} \sin \left(\theta_{v}+\theta\right)\right]}{H}} \cos \frac{M\left[r_{0} \cos \theta_{v}-r_{0} e^{\theta \tan \varphi^{\prime}} \cos \left(\theta_{v}+\theta\right)\right]}{H}\right]
$$

thus, the pore pressure along the failure surface can be obtained,

$$
u=\gamma_{w}\left[h-r_{0} \cos \theta_{v}+r_{0} \mathrm{e}^{\theta \tan \varphi^{\prime}} \cos \left(\theta_{v}+\theta\right)\right]
$$

Integration of Eq. (7) yields the resultant pore pressure force $U$ along the curved failure surface, which is given by

$$
U=\int u \mathrm{~d} s
$$

In Eq. (8), $u$ is the pore pressure acting perpendicular to the curved failure surface, and its radial and circumferential components can be written as

$$
\left\{\begin{array}{l}
u_{\mathrm{r}}=u \cos \varphi^{\prime} \\
u_{\mathrm{c}}=u \sin \varphi^{\prime}
\end{array}\right.
$$

The horizontal component of the resultant pore pressure force $U_{\mathrm{h}}$ is then obtained, 


$$
\begin{aligned}
U_{\mathrm{h}} & =\int_{0}^{\theta_{\mathrm{m}}} u_{\mathrm{r}} r_{0} \mathrm{e}^{\theta \tan \varphi^{\prime}} \sin \left(\theta+\theta_{v}\right) \sec \varphi^{\prime} \mathrm{d} \theta-\int_{0}^{\theta_{\mathrm{m}}} u_{\mathrm{c}} r_{0} \mathrm{e}^{\theta \tan \varphi^{\prime}} \cos \left(\theta+\theta_{v}\right) \sec \varphi^{\prime} \mathrm{d} \theta \\
& =\int_{0}^{\theta_{\mathrm{m}}} u r_{0} \mathrm{e}^{\theta \tan \varphi^{\prime}} \sin \left(\theta+\theta_{v}-\varphi^{\prime}\right) \sec \varphi^{\prime} \mathrm{d} \theta
\end{aligned}
$$

Similarly, the vertical component $U_{v}$ of the resultant pore pressure force is,

$$
\begin{aligned}
U_{\mathrm{v}} & =\int_{0}^{\theta_{\mathrm{m}}} u_{\mathrm{r}} r_{0} \mathrm{e}^{\theta \tan \varphi^{\prime}} \cos \left(\theta+\theta_{v}\right) \sec \varphi^{\prime} \mathrm{d} \theta+\int_{0}^{\theta_{\mathrm{m}}} u_{\mathrm{c}} r_{0} \mathrm{e}^{\theta \tan \varphi^{\prime}} \sin \left(\theta+\theta_{v}\right) \sec \varphi^{\prime} \mathrm{d} \theta \\
& =\int_{0}^{\theta_{\mathrm{m}}} u r_{0} \mathrm{e}^{\theta \tan \varphi^{\prime}} \cos \left(\theta+\theta_{v}-\varphi^{\prime}\right) \sec \varphi^{\prime} \mathrm{d} \theta
\end{aligned}
$$

As the radial component of pore pressure $u_{r}$ passes through the pole of the log-spiral, its contribution to the moment equilibrium condition is null. Therefore, only the moment of the circumferential pore pressure $u_{\mathrm{c}}$ is contributed as

$$
M_{\mathrm{u}}=\int u_{\mathrm{c}} r_{0} \mathrm{e}^{\theta \tan \varphi^{\prime}} \mathrm{d} s=\int_{0}^{\theta_{\mathrm{m}}} u_{\mathrm{c}} r_{0}^{2} \mathrm{e}^{2 \theta \tan \varphi^{\prime}} \sec \varphi^{\prime} \mathrm{d} \theta=\int_{0}^{\theta_{\mathrm{m}}} u r_{0}^{2} \mathrm{e}^{2 \theta \tan \varphi^{\prime}} \tan \varphi^{\prime} \mathrm{d} \theta
$$

\section{Determination of passive earth pressure}

Force equilibrium conditions can be applied to determine the passive earth thrust $P_{\mathrm{p}}$, where the weight of the failure wedge $W$, the effective reaction force $R^{\prime}$ acting on the failure surface, and the resultant pore pressure force $U$ are all known. The calculation procedure of $W$ and $R^{\prime}$ is presented below. From these parameters the passive earth thrust $P_{\mathrm{p}}$ and its location of application can be obtained.

\section{Weight of the failure wedge}

Considering the log-spiral curved failure surface shown in Fig. 5, the weight of the failure wedge $W$ can be calculated by

$$
W=W_{1}-W_{2}-W_{3}
$$

in which $W_{1}$ is the weight of the log spiral part OAC, $W_{2}$ is the weight of the triangular part $\mathrm{OBC}$, and $W_{3}$ is the weight of the triangular part $\mathrm{OAB} . W_{1}, W_{2}$ and $W_{3}$, can be given below, 


$$
\left\{\begin{array}{l}
W_{1}=\int_{0}^{\theta_{\mathrm{m}}} \frac{1}{2} \gamma_{\mathrm{sat}}\left(r_{0} \mathrm{e}^{\theta_{\mathrm{m}} \tan \varphi^{\prime}}\right)^{2} \mathrm{~d} \theta=\frac{1}{4} \gamma_{\mathrm{sat}} \frac{r_{0}^{2}}{\tan \varphi}\left(\mathrm{e}^{2 \theta_{\mathrm{m}} \tan \varphi^{\prime}}-1\right) \\
W_{2}=\frac{1}{2} \gamma_{\mathrm{sat}}\left[X_{\mathrm{o}}\left(Y_{\mathrm{b}}-Y_{\mathrm{c}}\right)+X_{\mathrm{b}}\left(Y_{\mathrm{c}}-Y_{\mathrm{o}}\right)+X_{\mathrm{c}}\left(Y_{\mathrm{o}}-Y_{\mathrm{b}}\right)\right] \\
W_{3}=\frac{1}{2} \gamma_{\mathrm{sat}}\left[X_{\mathrm{o}}\left(Y_{\mathrm{a}}-Y_{\mathrm{b}}\right)+X_{\mathrm{a}}\left(Y_{\mathrm{b}}-Y_{\mathrm{o}}\right)+X_{\mathrm{b}}\left(Y_{\mathrm{o}}-Y_{\mathrm{a}}\right)\right]
\end{array}\right.
$$

where $\gamma_{\text {sat }}$ is the unit weight of saturated soil, $X_{i}$ and $Y_{i}$ are the $x$ and $y$ coordinates of point $i(i=\mathrm{O}, \mathrm{A}, \mathrm{B}$ and $\mathrm{C})$.

$X_{i}$ and $Y_{i}$ can be determined with the known initial radius $r_{0}(\mathrm{OA})$, the distances $\mathrm{OB}$ and OC, which can be calculated by

$$
\left\{\begin{array}{l}
O A=r_{0}=\frac{H \cos \beta}{\cos \left(\theta_{v}+\beta\right)} \\
O B=\frac{H \sin \theta_{v}}{\cos \left(\theta_{v}+\beta\right)} \\
O C=r_{0} \mathrm{e}^{\theta_{\mathrm{m}} \tan \varphi^{\prime}}
\end{array}\right.
$$

where $\beta$ is the angle between $\mathrm{OB}$ and the horizontal direction calculated by

$$
\beta=\tan ^{-1}\left[\frac{\mathrm{e}^{\theta_{\mathrm{m}} \tan \varphi^{\prime}} \cos \left(\theta_{\mathrm{cr}}+\varphi^{\prime}\right)}{\sin \theta_{v}}\right]
$$

Solution of the modified Kötter equation

For the cohesionless homogeneous soil under passive state, the distribution of soil reaction along the curved failure surface can be obtained by original Kötter (1903) equation (Fig. 6), which can be written as,

$$
\frac{\partial p}{\partial s}+2 p \tan \varphi \frac{\partial \alpha}{\partial s}-\gamma \sin (\alpha+\varphi)=0
$$

where $\alpha$ is the tangential angle at the differential point on the failure surface with respect to the horizontal axis; $\gamma$ is the unit weight of soils.

Dewaikar and Mohapatra (2003a, b) applied the Kötter (1903) equation to the limit 
equilibrium analysis of shallow foundation bearing capacity problems, which has also been applied to earth pressure problems by Kame (2012) and Patki et al. (2015b, 2017). Note that these studies are restricted to the conditions without seepage flow. By considering the effect of seepage flow in the backfill, the Kötter equation can be modified into (Carrillo 1942):

$$
\frac{\partial p^{\prime}}{\partial s}+2 p^{\prime} \tan \varphi^{\prime} \frac{\partial \alpha}{\partial s}-\gamma_{\mathrm{sat}} \sin \left(\alpha+\varphi^{\prime}\right)-\frac{\partial u}{\partial s} \cos \varphi^{\prime}+\frac{\partial u}{\partial R} \sin \varphi^{\prime}=0
$$

or

$$
\frac{\partial p^{\prime}}{\partial \alpha}+2 p^{\prime} \tan \varphi^{\prime}-\gamma_{\mathrm{sat}} R \sin \left(\alpha+\varphi^{\prime}\right)-\frac{\partial u}{\partial \alpha} \cos \varphi^{\prime}+\frac{\partial u}{\partial R} \cdot R \sin \varphi^{\prime}=0
$$

where $R$ is the curvature radius along the curved failure surface.

In a polar coordinate system with $x=R \cdot \sin \alpha$ and $y=H-R \cdot \cos \alpha$, the total head of water $h$ can be expressed as

$$
h=(H-R \cos \alpha)+\frac{u}{\gamma_{w}}
$$

The derivatives of pore water pressure $u$ with respect to $\alpha$ and $R$ can then be obtained as

$$
\left\{\begin{array}{l}
\frac{\partial u}{\partial \alpha}=\gamma_{w}\left(\frac{\partial h}{\partial \alpha}-R \sin \alpha\right) \\
\frac{\partial u}{\partial R}=\gamma_{w}\left(\frac{\partial h}{\partial R}+\cos \alpha\right)
\end{array}\right.
$$

Substituting Eq. (21) into Eq. (19), the modified Kötter equation can be written into

$$
\frac{\partial p^{\prime}}{\partial \alpha}+2 p^{\prime} \tan \varphi^{\prime}-\gamma_{\mathrm{sat}} R \sin \left(\alpha+\varphi^{\prime}\right)-\gamma_{w}\left(\frac{\partial h}{\partial \alpha}-R \sin \alpha\right) \cos \varphi^{\prime}+\gamma_{w}\left(\frac{\partial h}{\partial R}+\cos \alpha\right) \cdot R \sin \varphi^{\prime}=0
$$

or

$$
\frac{\partial p^{\prime}}{\partial \alpha}+2 p^{\prime} \tan \varphi^{\prime}-\underbrace{\left(\gamma_{\text {sat }}-\gamma_{w}\right) R \sin \left(\alpha+\varphi^{\prime}\right)}_{\text {Buoyancy effect }}-\underbrace{\gamma_{w}\left(\frac{\partial h}{\partial \alpha} \cos \varphi^{\prime}-\frac{\partial h}{\partial R} R \sin \varphi^{\prime}\right)}_{\text {Seepage effect }}=0
$$

As seen in Eq. (23), the effect caused by the presence of water has two parts, i.e. 
buoyancy force and seepage force. For the special case of saturated soil without seepage inside the backfill or a planar failure surface concerned, the solution to Eq. (23) can be analytically obtained, as described in Appendix A. However, for the case with a log-spiral failure surface considering seepage effect, there is no analytical solution to the modified Kötter equation expressed in Eq. (23). Instead, a numerical procedure based on Runge-Kutta method was applied to solve the modified Kötter equation using the commercial software MATLAB. The effective reactive pressure $p^{\prime}$ under given boundary conditions can thus be obtained.

The total reactive pressure $p$ along the failure surface is then obtained by summing up the effective pressure $p^{\prime}$ and pore water pressure $u$. The integration of Eq. (23) gives the effective reactive pressure distribution, and double integration yields the effective resultant soil reaction $R^{\prime}$ on the log-spiral failure surface. Therefore, the horizontal and vertical components of the effective resultant soil reaction are given by

$$
\left\{\begin{array}{l}
R_{\mathrm{h}}{ }^{\prime}=\int_{0}^{\theta_{\mathrm{m}}} p^{\prime} r_{0} \mathrm{e}^{\theta \tan \varphi^{\prime}} \sin \left(\theta+\theta_{v}\right) \sec \varphi^{\prime} \mathrm{d} \theta \\
R_{\mathrm{v}}{ }^{\prime}=\int_{0}^{\theta_{\mathrm{m}}} p^{\prime} r_{0} \mathrm{e}^{\theta \tan \varphi^{\prime}} \cos \left(\theta+\theta_{v}\right) \sec \varphi^{\prime} \mathrm{d} \theta
\end{array}\right.
$$

Passive earth pressure solution

The passive earth pressure acting on the retaining wall can be obtained using force equilibrium conditions in both the horizontal and vertical directions. Considering the horizontal force equilibrium illustrated in Fig. 2, the horizontal component of the passive earth thrust can be expressed as

$$
P_{\mathrm{h}}=R_{\mathrm{h}}{ }^{\prime}+U_{\mathrm{h}}
$$


Similarly, vertical force equilibrium gives the vertical component as

$$
P_{\mathrm{v}}=U_{\mathrm{v}}+R_{\mathrm{v}}{ }^{\prime}-W
$$

Combining Eqs. (25) and (26) yields

$$
P_{\mathrm{p}}=\frac{P_{\mathrm{h}}}{\cos \delta}=\frac{R_{\mathrm{h}}{ }^{\prime}+U_{\mathrm{h}}}{\cos \delta}
$$

or

$$
P_{\mathrm{p}}=\frac{P_{\mathrm{v}}}{\sin \delta}=\frac{U_{\mathrm{v}}+R_{\mathrm{v}}{ }^{\prime}-W}{\sin \delta}
$$

As illustrated in the flowchart in Fig. 3, the iterative procedure can be repeated until the discrepancy between the two values of $P_{\mathrm{p}}$ is within a prescribed tolerance, which is set as $0.1 \%$ of the mean value of $P_{\mathrm{p}}$ obtained using Eqs. (27) and (28) in the present study.

Location of the passive thrust

Considering the moment equilibrium condition on the pole of the log spiral $O$, the distance $T$ is then obtained by

$$
T=O A \cos \theta_{\mathrm{v}}-\frac{W_{1} L_{1}-W_{2} L_{2}-W_{3} L_{3}-M_{\mathrm{u}}+P_{\mathrm{v}} O B \cos \beta}{P_{\mathrm{h}}}
$$

where $L_{1}, L_{2}$ and $L_{3}$ are the horizontal distances between the centers of gravity of OAC, $O B C$ and $O A B$ and point $O$, respectively, as shown in Fig. 5, and can be obtained by

$$
\left\{\begin{array}{l}
L_{1}=n_{1} \cos \theta_{\mathrm{v}}+n_{2} \sin \theta_{\mathrm{v}} \\
L_{2}=\frac{X_{\mathrm{o}}+X_{\mathrm{b}}+X_{\mathrm{c}}}{3} \\
L_{3}=\frac{X_{\mathrm{o}}+X_{\mathrm{a}}+X_{\mathrm{b}}}{3}
\end{array}\right.
$$

where 


$$
\left\{\begin{array}{l}
n_{1}=\frac{4 r_{0} \tan \varphi^{\prime}}{3\left(1+9 \tan ^{2} \varphi^{\prime}\right)} \frac{\mathrm{e}^{3 \theta_{\mathrm{m}} \tan \varphi^{\prime}}\left(\sin \theta_{\mathrm{m}}+3 \tan \varphi^{\prime} \cos \theta_{\mathrm{m}}\right)-3 \tan \varphi^{\prime}}{\mathrm{e}^{2 \theta_{\mathrm{m}} \tan \varphi^{\prime}}-1} \\
n_{2}=\frac{4 r_{0} \tan \varphi^{\prime}}{3\left(1+9 \tan ^{2} \varphi^{\prime}\right)} \frac{1-\mathrm{e}^{3 \theta_{\mathrm{m}} \tan \varphi^{\prime}}\left(\cos \theta_{\mathrm{m}}-3 \tan \varphi^{\prime} \sin \theta_{\mathrm{m}}\right)}{\mathrm{e}^{2 \theta_{\mathrm{m}} \tan \varphi^{\prime}}-1}
\end{array}\right.
$$

As indicated in the flowchart (Fig. 3), several passive thrusts $P_{\mathrm{p}}$ can be obtained that satisfy the conditions set out in this study, while the locations of $P_{\mathrm{p}}$ may vary. It has been shown that in most cases, the application of the passive thrust $P_{\mathrm{p}}$ is located at 1/3H, which yields the optimum result (Barros 2006; Xu et al. 2015; Patki et al. 2017). Therefore, the $1 / 3 H$ criterion is adopted for selecting the optimum passive thrust $P_{\mathrm{p}}$, and from this the coefficient of passive earth pressure considering seepage flow $K_{\mathrm{p}}$ can be obtained,

$$
K_{\mathrm{p}}=\frac{2 P_{\mathrm{p}}}{\gamma_{\mathrm{sat}} H^{2}}
$$

Parametric analysis

Some of the key parameters that may influence the passive earth pressure including the ratio of permeability coefficient $\xi$, the effective friction angle $\varphi^{\prime}$ and the soil-wall interface friction angle $\delta$ are considered during the parametric analysis. Fig. 7 presents the influence of anisotropic seepage flow on the coefficient of passive earth pressure $K_{\mathrm{p}}$, in which $\varphi^{\prime}$ varies within the range of $20^{\circ}-45^{\circ}$ while the condition $\delta=1 / 2 \varphi^{\prime}$ is maintained. It is noted that the value of the ratio of permeability coefficient $\xi$ is assumed to vary from 0 to 1 , as the horizontal permeability coefficient is normally greater than the vertical $\left(k_{x} / k_{y}>1\right)$ in normal sedimentary deposits as well as the backfill behind the retaining walls (Taylor 1948; Harr 1962; Kenny 1963; Head 1988; Rafiezadeh and Ashtiani 2014). Three values of $\xi(=1 / 3,1 / 2$ and $2 / 3)$ are 
taken in the analysis to represent the expected range, in comparison with the isotropic seepage flow with $\xi=1.0$. As illustrated in Fig. 7, the influence of the anisotropic seepage flow is insignificant when $\varphi^{\prime}<30^{\circ}$, while such influence becomes considerable when $\varphi^{\prime}>30^{\circ}$. For example, the maximum difference when $\varphi^{\prime}=35^{\circ}$ is about $15 \%$, while the isotropic case $\xi=1.0$ provides the lower bound.

Fig. 8 presents the influence of the internal friction angle $\varphi^{\prime}$ on the passive earth pressure for varying soil-wall interface friction angles $\delta$. In this case, only isotropic seepage flow with $\xi=1$ inside the backfill is considered. Similar trends are observed with those from earlier studies, such as Soubra and Macuh (2002) and Barros (2006), that $K_{\mathrm{p}}$ increases with $\varphi^{\prime}$ for a range of $\delta$ values. Note that Patki et al. (2017) applied a similar procedure to calculate the passive earth pressure. However they did not consider the effect of seepage flow in the backfill. Compared to the present study, their results overestimate the passive earth pressure and thus may give rise to un-conservative values if they were applied in a practical engineering design. Moreover, the difference is moderate when $\varphi^{\prime}$ and $\delta$ are small, but it grows when $\varphi^{\prime}$ and $\delta$ become larger; for example the difference is approximately $40 \%$ when $\varphi^{\prime}=\delta=45^{\circ}$.

To further assess the joint effects of anisotropic seepage flow and the soil-wall interface friction angle $\delta$, Fig. 9 presents the coefficient of passive earth pressure $K_{\mathrm{p}}$ varying with friction angle $\varphi^{\prime}$ and $\delta$ under both isotropic $(\xi=1)$ and anisotropic $(\xi=1 / 3)$ conditions. Overall, the results show that $K_{\mathrm{p}}$ increases with the interface friction angle and soil internal friction angle. For the cases with smaller $\varphi^{\prime}$ and $\delta$, the effect of 
anisotropy of seepage flow is relatively small, while the difference between the isotropic and anisotropic cases become larger when $\varphi^{\prime}$ and $\delta$ increase. Comparison between $\xi=1 / 3$ and $\xi=1$ indicates that the anisotropic seepage flow will increase the passive earth pressure, especially when $\varphi^{\prime}$ and $\delta$ are larger. For example, a more than $16 \%$ discrepancy is shown in Fig. 9 when $\varphi^{\prime}=\delta=35^{\circ}$.

\section{Simplified procedure}

When calculating the passive earth pressure, the curved failure surface is commonly assumed, in accordance with those observed in practical engineering (Morrison and Ebeling 1995; Subba Rao and Choudhury 2005), although it may bring in more complex implementation procedures. Nevertheless, as has been shown that for cases with the soil-wall interface friction angle $\delta$ smaller than $\varphi^{\prime} / 2$, the discrepancy between the real failure surface and Coulomb's planar surface is very small, especially for small effective internal friction angles $\varphi^{\prime}$ (Murthy 2002). Therefore, the passive earth pressure can also be computed under such conditions by assuming a simplified planar failure surface. Given the advantages of the planar failure surface, this simplification is assessed for validity given the presence of seepage flow within the backfill. Similar to the analysis for curved failure surfaces, the flow field could be obtained using the Laplace equation, and the modified Kötter equation (Eq. 23) is applied to calculate the effective reactive force along the planar failure surface. Fig. 10 illustrates the simplified free body diagram in the analysis. 
Pore pressure along the planar failure surface

After substituting $x=y \cdot \cot (\varepsilon)$ into Eq. (2), the total head along the planar failure surface can be obtained as

$$
h(y, \varepsilon)=H\left[1-\sum_{m=0}^{\infty} \frac{2}{M^{2}} \mathrm{e}^{-\frac{M y \xi \cot \varepsilon}{H}} \cos \frac{M y}{H}\right]
$$

and the pore pressure at any point along the planar failure surface is

$$
u(y, \varepsilon)=\gamma_{w}[h(y, \varepsilon)-y]
$$

Integration of Eq. (34) yields the resultant pore pressure force $U$ on the planar failure surface, given by

$$
U=\int_{0}^{H} u \csc \varepsilon \mathrm{d} y
$$

Simplified passive earth pressure solution

Based on the horizontal and vertical equilibrium conditions, the components of passive earth pressure in both directions can be expressed as

$$
\left\{\begin{array}{l}
P_{\mathrm{hs}}=U \sin \varepsilon+R_{\mathrm{s}}{ }^{\prime} \sin \left(\varepsilon+\varphi^{\prime}\right) \\
P_{\mathrm{vs}}=U \cos \varepsilon+R_{\mathrm{s}}{ }^{\prime} \cos \left(\varepsilon+\varphi^{\prime}\right)-W
\end{array}\right.
$$

where the weight of the failure wedge is

$$
W=\frac{1}{2} \gamma_{\text {sat }} H^{2} \cot \varepsilon
$$

and the effective resultant soil reaction $R_{\mathrm{s}}{ }^{\prime}$ acting on the planar failure surface is

$$
R_{\mathrm{s}}^{\prime}=\gamma^{\prime} \sin \left(\varepsilon+\varphi^{\prime}\right) \frac{(H \csc \varepsilon)^{2}}{2}
$$

The detailed derivation of Eq. (38) is presented in Appendix A2.

Then, the passive earth pressure from this simplified method is obtained as

$$
P_{\mathrm{ps}}=\frac{P_{\mathrm{hs}}}{\cos \delta}=\frac{P_{\mathrm{vs}}}{\sin \delta}
$$

By applying the moment equilibrium condition on point $D$, the unique application of 
the simplified passive thrust $P_{\mathrm{ps}}$ is then obtained,

$$
T_{\mathrm{s}}=\frac{\int_{0}^{H} u(\csc \varepsilon)^{2} y \mathrm{~d} y+\frac{1}{3} R_{\mathrm{s}}^{\prime} H \csc \varepsilon \cos \varphi^{\prime}-\frac{1}{3} W H \cot \varepsilon}{P_{\mathrm{hs}}}
$$

Unlike the previous method adopting the curved failure surface, the simplified method only requires a single parameter $\varepsilon$ to obtain the complete geometry of the planar failure wedge. The passive earth pressure can be obtained when the parameters $\varphi^{\prime}, \delta$ and $H$ are known. The results from the simplified method and comparisons with the curved failure surface approach are discussed below.

Comparison with the curved failure surface

To evaluate the accuracy of the planar failure surface assumption on the passive earth pressure, comparisons are made between the results from both methods considering anisotropic seepage flow inside the backfill. For this comparison, $\varphi^{\prime}$ varies from $20^{\circ}$ to $45^{\circ}$ while the condition $\delta=1 / 2 \varphi^{\prime}$ is maintained. As shown in Fig. 11, overall, the results from the planar failure surface overestimate the passive earth pressure, and the differences become more significant as $\varphi^{\prime}$ increases. However, when $\varphi^{\prime}$ is small, the discrepancy is negligible. For example, the differences between these two results are only about $4 \%$ and $6 \%$ when $\varphi^{\prime}=20^{\circ}$ and $30^{\circ}$, respectively. On this basis, the simplified method can be appropriately applied to calculate the passive earth pressure including the effects of seepage flow inside the backfill when $\varphi^{\prime} \leq 30^{\circ}$ and $\delta=1 / 2 \varphi^{\prime}$ 


\section{Validation and Discussion}

Comparison with the results of Shields and Tolunay (1973)

The passive earth pressure acting on a vertical retaining wall with horizontal backfill can be calculated following the procedure outlined above. The backfill is fully saturated sand with seepage flow inside the backfill. Using the procedure illustrated in Fig. 3, a unique log-spiral failure surface can be obtained and thus the passive earth pressure can be calculated. Note that the modified Kötter equation is employed to compute the effective soil reactive pressure distribution on the failure surfaces presented, force-equilibrium analysis can be directly performed without pre-assuming the location of the earth thrust.

Shields and Tolunay (1973) reported the passive earth pressure coefficients using the method of slices, in which a composite curved (log-spiral and planar) failure surface was adopted but the effects of seepage flow were not considered in their analysis. In comparison in this study the modified Kötter equation is employed to obtain the effective reactive force along the proposed curved failure surface, and thus the corresponding $P_{\mathrm{p}}$ values can be obtained by applying force-equilibrium conditions. To verify whether the failure surfaces adopted by Shield and Tolunay (1973) are capable of fulfilling the force-equilibrium conditions, the Kötter equation was also used to compute the reactive force along the failure surface proposed by Shield and Tolunay (1973). Similar analyses were also undertaken by Patki et al. (2017) to discuss the equilibrium conditions of their failure surface, in which the seepage flow in the backfill was excluded. 
Table 1 lists the passive thrusts $P_{\mathrm{p}}$ obtained using the modified Kötter (1903) equation for the composite curved failure surface proposed by Shields and Tolunay (1973) and the log-spiral failure surface proposed in this study. The unit weight of the saturated backfill is equal to $20 \mathrm{kN} / \mathrm{m}^{3}$, the effective friction angle $\varphi^{\prime}$ varies from $20^{\circ}$ to $45^{\circ}$, and the soil-wall friction angle $\delta$ is taken as $1 / 2 \varphi^{\prime}$. It is seen from Table 1 that the passive earth thrusts $P_{\mathrm{p}}$ from both methods show very close results, with the difference being about $4 \%$ when $\varphi^{\prime}=35^{\circ}$. However, the $P_{\mathrm{p}}$ values using Kötter (1903) equation for Shields and Tolunay's (1973) failure surface show relatively large difference between the results obtained from the horizontal and vertical directions (i.e. $P_{\mathrm{p}}{ }^{\mathrm{h}}$ and $P_{\mathrm{p}}^{\mathrm{v}}$ ), thus the failure surface proposed by Shields and Tolunay (1973) does not fulfill the force-equilibrium conditions. Table 1 also lists the horizontal and vertical components of the passive earth thrust from both methods (i.e. $P_{\mathrm{h}}$ and $P_{\mathrm{v}}$ ). As followed by the standard sign convention in Table 1, the downward vertical component of the passive thrust $P_{\mathrm{v}}$ is taken to be positive, due to the influence of the soil-wall interface friction. Shield and Tolunay (1973) reported the passive earth pressure for the case of a clockwise-inclined retaining wall, resulting in a positive (or downward) vertical component of $P_{\mathrm{p}}$. However, as listed in the table, for the cases with $\varphi^{\prime} \leq 40^{\circ}$, the obtained $P_{v}$ values by Shields and Tolunay (1973) are all negative, indicating that the passive thrust $P_{\mathrm{p}}$ would be slightly upward. This direction of passive thrust is not what would be expected given the soil-wall interface friction. In comparison, the method proposed here yields positive results for both $P_{\mathrm{v}}$ and $P_{\mathrm{h}}$, in accordance with those normally used in the practical design. In addition, negligible 
discrepancies are observed between the results of $P_{\mathrm{p}}{ }^{\mathrm{h}}$ and $P_{\mathrm{p}}{ }^{\mathrm{v}}$, indicating that the failure mechanism adopted in this study fulfills the force equilibrium conditions with the criterion of the passive thrust $P_{\mathrm{p}}$ located at $1 / 3 \mathrm{H}$ of the retaining wall.

\section{Comparison with other theoretical results}

To further assess the effects of seepage flow on the passive earth pressure, Table 2 presents the comparisons of $K_{\mathrm{p}}$ values between the present study and other methods reported in the literature, including Soubra (2000), Shiau et al. (2008), Antão et al. (2011), Lancellotta (2002), and Patki et al. (2015b, 2017). Only isotropic seepage flow with $\xi=1$ is considered herein. The same ranges of the parameters as those in Table 1 are considered for a vertical retaining wall resting against a horizontal cohesionless backfill, while the effects of seepage flow were not taken into account in their analyses. Note that Soubra (2000) used the limit analysis method considering the kinematic conditions to obtain the upper-bound solutions of the passive earth pressure. Shiau et al. (2008) and Antão et al. (2011) adopted the limit analysis coupled with the finite element method, and obtained the upper-bound solutions of passive earth pressure. In comparison, Lancellotta (2002) proposed an analytical lower-bound solution based on the limit analysis method. The limit equilibrium method coupled with the original Kötter equation was employed by Patki et al. (2015b, 2017), with the former adopting the composite failure surface comprising a log spiral followed by its tangent and the latter adopting the complete log-spiral failure surface. The resultant earth reaction distributing on the curved failure surface was directly obtained by solving the original Kötter equation. 
As seen in Table 2, the $K_{\mathrm{p}}$ values using the proposed method employing the log-spiral failure surface are in fairly good agreements with the theoretical results from the studies outlined above. Because the method proposed in this study accounts for seepage flow effects, it yields smaller $K_{\mathrm{p}}$ values than those obtained by the other methods, as evidenced by Table 2. It is also noted that the discrepancy grows as $\varphi^{\prime}$ and $\delta$ increase; for example it could be $10-40 \%$ lower than the results obtained by Patki et al. (2017), which is a special case of the proposed method if seepage flow is not addressed in the backfill.

It is worth noting that the passive earth thrust is regarded as the main supporting force ensuring the stability of the retaining structures in design. When there exists the seepage flow inside the backfill, the passive earth pressures will be decreased, and the ultimate capacity of the retaining structure will be reduced, leading to the potential for instability problems during the retaining walls design life. In such cases, it is of vital importance to account for the effects of seepage flow during design calculations.

\section{Conclusions}

This paper presents an analytical procedure to calculate the passive earth pressure acting on a retaining wall, considering the anisotropic seepage flow through a cohesionless backfill. The main focus of this paper is the effect of anisotropic seepage flow on the passive earth pressure, when applied to more realistic failure surfaces. The conclusions of this work are summarized below: 
1) A log-spiral failure surface was employed to derive the passive earth pressure based on the limit equilibrium method. The trial and error procedure performed to obtain the potential passive earth pressure solutions including anisotropic seepage did not require a pre-assumed location of the earth thrust in force equilibrium analysis.

2) Using a Fourier series expansion method and coordinate transformation technique, the anisotropic seepage field in the backfill behind the retaining wall can be analytically solved for the required boundary conditions, and thus the pore water pressure acting on either curved or planar failure surfaces can be obtained.

3) The modified Kötter equation considering the effect of anisotropic seepage flow was employed to compute the effective soil reactive pressure distribution on the log-spiral failure surfaces. An iterative procedure based on force equilibrium conditions can be performed to identify a unique failure surface and thus the passive earth thrust.

4) The passive earth pressure is greatly reduced due to the existence of seepage flow in the backfill, and this is detrimental to the stability of the retaining structures. The influence of anisotropic seepage flow was investigated by varying the ratios of the permeability coefficient $\xi$. In comparison to the isotropic seepage case, the passive earth pressure is increased when seepage is anisotropic. The discrepancy is greater as $\xi$ increases. In the case of $\varphi^{\prime}=\delta=45^{\circ}$, the calculated $P_{\mathrm{p}}$ with seepage is decreased by $40 \%$ in comparison to the results without the seepage flow.

5) A parametric study indicates that the passive earth pressure coefficient $K_{\mathrm{p}}$ varies 
both with the soil-wall interface friction angle $\delta$ and with the internal friction angle of soils $\varphi^{\prime}$. Large values of both $\varphi^{\prime}$ and $\delta$ will increase the passive earth pressure, which is beneficial to the stability of retaining structures.

6) A simplified version that employs a planar failure surface to replace the curved one was proposed. It has been shown that under seepage flow conditions the simplified method yields similar results to the curved failure surface where $\varphi^{\prime} \leq 30^{\circ}$ and $\delta=1 / 2 \varphi^{\prime}$. The discrepancy is approximately $4 \%$ and $6 \%$ when $\varphi^{\prime}=20^{\circ}$ and $30^{\circ}$, respectively.

The calculation procedure proposed in this study is applicable to the passive earth pressure under anisotropic seepage flow conditions in the backfill behind a vertical wall where the top of the backfill is horizontal. For more complicated ground conditions, such as a non-level ground surface and multi-layered backfill, further analysis is required to generate a more general solution which can deal with the full range of conditions normally encountered in engineering practice. It should also be noted that due to the heavy rainfall, the velocity of the seepage flow may exceed the range of the steady laminar flow, under these conditions, the nonlinear Darcy's law should be applied to obtain the seepage forces inside the backfill. In addition, internal erosion may occur such that the particles, especially fine particles are pulled away by the seepage forces. This design aspect is of particular concern and deserves further study.

\section{Acknowledgements}

The research described in this paper was supported by the National Key Basic 
Research Program of China (No. 2015CB057801), the National Key R \& D program of China (No. 2016YFC0800204), and Natural Science Foundation of China (Nos. 51578499 \& 51761130078), which is gratefully acknowledged.

\section{List of the symbols}

$H \quad$ height of retaining wall

h total water head

$K_{\mathrm{p}} \quad$ coefficient of passive earth pressure

$k_{\mathrm{x}}, k_{\mathrm{y}} \quad$ coefficients of permeability in the horizontal and vertical directions, respectively

$L_{i} \quad$ horizontal distance of the portions from the pole of the log spiral

$m, M$ number of term in Fourier series, and $M=(2 m+1) \pi / 2$, respectively

$M_{\mathrm{o}}, M_{\mathrm{u}} \quad$ moment of the total force and the pore water pressure about the pole of the log spiral, respectively

$n_{i} \quad$ distance of the point of application of the portions from the pole of the log spiral

$p, p^{\prime} \quad$ soil reactive pressure and effective reactive pressure, on the failure surface, respectively

$P_{\mathrm{p}}, P_{\mathrm{h}}, P_{\mathrm{v}} \quad$ resultant, horizontal and vertical components of passive thrust acting on the retaining wall, respectively

$P_{\mathrm{ps}}, P_{\mathrm{hs}}, P_{\mathrm{vs}}$ resultant, horizontal and vertical components of passive 
thrust acting on the retaining wall in simplified method, respectively

$r, r_{0} \quad$ intermediate and initial radius of the log spiral, respectively

$R \quad$ curvature radius of points along the curved failure surface

$R^{\prime}, R_{\mathrm{h}}{ }^{\prime}, R_{\mathrm{v}}{ }^{\prime} \quad$ resultant, horizontal and vertical components of effective resultant soil reaction offered by the failure surface, respectively

$R_{\mathrm{s}}{ }^{\prime}, R_{\mathrm{hs}}{ }^{\prime}, R_{\mathrm{vs}}{ }^{\prime}$ resulant, horizontal and vertical components of effective resultant soil reaction in the simplified method, respectively

$s \quad$ distance of a point measured from top of the failure surface in simplified method

$T, T_{\mathrm{s}} \quad$ distances between the wall toe and the point of the passive thrust using methods adopting curved and planar failure surfaces, respectively

$U, U_{h}, U_{v} \quad$ resultant, horizontal and vertical components of resultant pore water pressure force acting on the failure surface, respectively

$u, u_{r}, u_{c} \quad$ resultant, radial and circumferential components of pore water pressure, respectively

W self-weight of the failure wedge

$W_{i} \quad$ weight of the log spiral and triangular portion, $i=1-3$

$X_{i}$ and $Y_{i} \quad \mathrm{x}$ and $\mathrm{y}$ coordinate of the point $\mathrm{O}, \mathrm{A}, \mathrm{B}$ and $\mathrm{C}$, respectively

$\alpha \quad$ angle between the horizontal and the tangent to the 
differential point on the failure surface

elevation angle of the top of retaining wall

$\gamma, \gamma^{\prime} \quad$ unit weight and effective unit weight of soil, respectively

$\gamma_{\text {sat }}, \gamma_{\mathrm{w}} \quad$ unit weights of saturated soil and water, respectively

$\delta$

soil-wall interface friction angle

$\varepsilon$

angle between the planar failure surface and the horizontal

direction in simplified method

$\theta, \theta_{\mathrm{m}} \quad$ angle made by the intermediate radii, the final radii of the log

spiral with the initial radii, respectively

$\theta_{v} \quad$ angle made by the initial radii of the log spiral with the wall

$\theta_{\mathrm{cr}} \quad$ angle made by the tangent to the log spiral with horizontal at the tail end portion

$\xi \quad$ ratio of permeability coefficients between $k_{\mathrm{x}}$ and $k_{\mathrm{y}}$

$\varphi, \varphi^{\prime} \quad$ internal friction angle and effective internal friction angle of

soil 


\section{References}

Ai, Z.Y., and Hu, Y.D. 2015. A coupled BEM-ALEM approach for analysis of elastic thin plates on multilayered soil with anisotropic permeability. Engineering Analysis with Boundary Elements, 53: 40-45.

$\mathrm{Ai}$, Z.Y., and $\mathrm{Wu}, \mathrm{C}$. 2009. Plane strain consolidation of soil layer with anisotropic permeability. Applied Mathematics and Mechanics, 30(11): 1437-1444.

Antão, A.N., Santana, T.G., Vicente da Silva, M., and da Costa Guerra, N.M. 2011. Passive earth-pressure coefficients by upper-bound numerical limit analysis. Canadian Geotechnical Journal, 48(5): 767-780.

Barros, P.L.A., and Santos, P.J. 2012. Coefficients of active earth pressure with seepage effect. Canadian Geotechnical Journal, 49(6): 651-658.

Barros, P.L.A. 2006. Coulomb-type solution for active earth thrust with seepage. Géotechnique, 56(3): 159-164.

Benmebarek, N., Benmebarek, S., Kastner, R., and Soubra, A.H. 2006. Passive and active earth pressures in the presence of groundwater flow. Géotechnique, 56(3): 149-158.

Bishop, A.W. 1966. The strength of soils as engineering materials. Géotechnique, 16(2): 91-130.

Brandenberg, S.J., Mylonakis, G., and Stewart, J.P. 2015. Kinematic framework for evaluating seismic earth pressures on retaining walls. Journal of Geotechnical and Geoenvironmental Engineering, 141(7): 04015031.

Budhu, M. 2011. Soil mechanics and foundations. John Wiley \& Sons, New York. 
Chen, Z.Y., and Li, S.M. 1998. Evaluation of active earth pressure by the generalized method of slices. Canadian Geotechnical Journal, 35(4): 591-599.

Cheng, Y.M. 2003. Seismic lateral earth pressure coefficients for $c-\varphi$ soils by slip line method. Computers and Geotechnics, 30(8): 661-670.

Carrillo, N. 1942. Differential equation of a sliding surface in an ideal saturated plastic soil. Studies in Applied Mathematics, 21(1-4): 6-9.

Collins, I.F. 1973. A note on the interpretation of Coulomb's analysis of the thrust on a rough retaining wall in terms of the limit theorems of plasticity theory. Géotechnique, 23(3): 442-447.

Coulomb, C.A. 1776. Essai sur une application des règles des maximis et minimis à quelques problèmes de statique relatifs à l'architecture. Mémoires de mathématique et de physique, présentés à l’academie Royale des Sciences, Paris, 7: 343-382.

Dewaikar, D.M., and Mohapatra, B.G. 2003a. Computation of bearing capacity factor $\mathrm{N}_{\psi}$-Prandtl's mechanism. Soils and Foundations, 43(3): 1-10.

Dewaikar, D.M., and Mohapatro, B.G. 2003b. Computation of bearing capacity factor $\mathrm{N}_{\psi}$-Terzaghi's mechanism. International Journal of Geomechanics, 3(1): 123-128.

Fang, Y.S., Ho, Y.C., and Chen, T.J. 2002. Passive earth pressure with critical state concept. Journal of Geotechnical and Geoenvironmental Engineering, 128(8): 651-659.

Fang, Y.S., and Ishibashi, I. 1986. Static earth pressures with various wall movements. Journal of Geotechnical Engineering, 112(3): 317-333. 
Ghosh, P. 2008. Seismic active earth pressure behind a nonvertical retaining wall using pseudo-dynamic analysis. Canadian Geotechnical Journal, 45(1): 117-123.

Ghosh, S., and Sharma, R.P. 2012. Pseudo-dynamic evaluation of passive response on the back of a retaining wall supporting $c-\varphi$ backfill. Geomechanics and Geoengineering, 7(2): 115-121.

Harr, M.E. 1962. Groundwater and seepage. McGraw-Hill, New York.

Hazelton, P., and Murphy, B. 2007. Interpreting soil test results. Csiro, Collingwood.

Head, K.H. 1988. Manual of soil laboratory testing, vol. 2, permeability, shear strength and compressibility tests. Pentech Press, London.

Helwany, S. 2007. Applied soil mechanics with ABAQUS applications. John Wiley \& Sons, New Jersey.

Hu, Z., Yang Z.X., and Wilkinson, S.P. 2017. Active earth pressure acting on retaining wall considering anisotropic seepage effect. Journal of Mountain Science. 14(6): $1202-1211$.

Ichihara, M., Matsuzawa, H., Kawamura, M. and Takeuchi, T. 1982. Influence of seepage flow on earth pressure against retaining wall. Soils and Foundations, 22(2): 15-28.

Jeng, D.S., Li, L., and Barry, D.A. 2001. Wave-induced seepage flux into anisotropic seabeds. International Journal for Numerical and Analytical Methods in Geomechanics, 25(8): 771-787.

Kame, G.S. 2012. Analysis of a continuous vertical plate anchor embedded in cohesionless soil. Ph. D. thesis, Department of Civil Engineering, Indian Institute 
of Technology, Bombay, India.

Kenney, T.C. 1963. Permeability ratio of repeatedly layered soils. Géotechnique, 13: 325-333.

Kötter, F. 1903. Die bestimmung des Druckes an gekrummten Gleitflachen, eine Aufgabe aus der Lehre Vom Ediddruck. Sitzungsberichteder Akademie der Wissenschaften, Berlin.

Kumar, J., and Chitikela, S. 2002. Seismic passive earth pressure coefficients using the method of characteristics. Canadian Geotechnical Journal, 39(2): 463-471.

Kumar, J. 2001. Seismic passive earth pressure coefficients for sands. Canadian Geotechnical Journal, 38(4): 876-881.

Lancellotta, R. 2002. Analytical solution of passive earth pressure. Géotechnique, 52(8): 617-619.

Liu, F.Q., and Wang, J.H. 2008. A generalized slip line solution to the active earth pressure on circular retaining walls. Computers and Geotechnics, 35(2): 155-164.

Morrison, E.E., and Ebeling, R.M. 1995. Limit equilibrium computation of dynamic passive earth pressure. Canadian Geotechnical Journal, 32(3): 481-487.

Motta, E. 1994. Generalized Coulomb active-earth pressure for distanced surcharge. Journal of Geotechnical Engineering, 120(6): 1072-1079.

Murthy, V.N.S. 2002. Geotechnical engineering: principles and practices of soil mechanics and foundation engineering. CRC Press.

Patki, M.A., Dewaikar, D.M., and Mandal, J.N. 2017. Numerical Study on Passive Earth 
Pressures Using Kötter's Equation. International Journal of Geomechanics, 17(2): 06016015.

Patki, M.A., Mandal, J.N., and Dewaikar, D.M. 2015a. A simple approach based on the limit equilibrium method for evaluating passive earth pressure coefficients. Geotechnik, 38(2): 120-133.

Patki, M.A., Mandal, J.N., and Dewaikar, D.M. 2015b. Determination of passive earth pressure coefficients using limit equilibrium approach coupled with the Kötter equation. Canadian Geotechnical Journal, 52(9): 1241-1254.

Rafiezadeh, K., and Ataie-Ashtiani, B. 2014. Transient free-surface seepage in three-dimensional general anisotropic media by BEM. Engineering Analysis with Boundary Elements, 46: 51-66.

Rankine, W.J.M. 1857. On the stability of loose earth. Philosophical Transactions of the Royal Society of London, 147: 9-27.

Sabzevari, A., and Ghahramani, A. 1973. Theoretical Investigations of the Passive Progressive Failure in an Earth Pressure Problem. Soils and Foundations, 13(2): 1-18.

Santos, P.J., and Barros, P.L.A. 2015. Active earth pressure due to soil mass partially subjected to water seepage. Canadian Geotechnical Journal, 52(11): 1886-1891.

Shiau, J.S., Augarde, C.E., Lyamin, A.V., and Sloan, S.W. 2008. Finite element limit analysis of passive earth resistance in cohesionless soils. Soils and Foundations, 48(6): 843-850.

Shields, D.H., and Tolunay, Z.A. 1973. Passive pressure coefficients by method of 
slices. Journal of Geotechnical and Geoenvironmental Engineering, 99: 1043-1053.

Siddiqua, S., Blatz, J.A., and Privat, N.C. 2013. Evaluating the behaviour of instrumented prototype rockfill dams. Canadian Geotechnical Journal, 50(3), 298-310.

Siddiqua, S., Blatz, J., and Siemens, G. 2011. Evaluation of the impact of pore fluid chemistry on the hydromechanical behaviour of clay-based sealing materials. Canadian Geotechnical Journal, 48(2), 199-213.

Škrabl, S., and Macuh, B. 2005. Upper-bound solutions of three-dimensional passive earth pressures. Canadian Geotechnical Journal, 42(5): 1449-1460.

Sokolovskii, V.V. 1965. Statistics of granular media. Pergamon, London.

Soubra, A.H., Kastner, R., and Benmansour, A. 1999. Passive earth pressures in the presence of hydraulic gradients. Géotechnique, 49(3): 319-330.

Soubra, A.H., and Macuh, B. 2002. Active and passive earth pressure coefficients by a kinematical approach. Proceedings of the Institution of Civil Engineers-Geotechnical Engineering, 155(2): 119-131.

Soubra, A.H. 2000. Static and seismic passive earth pressure coefficients on rigid retaining structures. Canadian Geotechnical Journal, 37(2): 463-478.

Subba Rao, K.S., and Choudhury, D. 2005. Seismic passive earth pressures in soils. Journal of Geotechnical and Geoenvironmental Engineering, 131(1): 131-135.

Taylor, D.W. 1948. Fundamentals of soil mechanics. Soil Science, 66(2): 161. 
Terzaghi, K., Peck, R.B., and Mesri, G. 1996. Soil mechanics in engineering practice. 3rd Edition, John Wiley \& Sons.

Terzaghi, K. 1941. General wedge theory of earth pressure. American Society of Civil Engineers Transactions, 106: 68-80.

Veiskarami, M., and Zanj, A. 2014. Stability of sheet-pile walls subjected to seepage flow by slip lines and finite elements. Géotechnique, 64(10): 759-775.

Wang, J.J., Liu, F.C., and Ji, C.L. 2008a. Influence of drainage condition on Coulomb-type active earth pressure. Soil Mechanics and Foundation Engineering, 45: 161-167.

Wang, J.J., Zhang, H.P., Chai, H.J., and Zhu, J.G. 2008b. Seismic passive resistance with vertical seepage and surcharge. Soil Dynamics and Earthquake Engineering, 28(9): 728-737.

Wang, Y.H., and Cheung, Y.K. 2001. Plate on cross-anisotropic foundation analyzed by the finite element method. Computers and Geotechnics, 28(1): 37-54.

Xu, S.Y., Shamsabadi, A., and Taciroglu, E. 2015. Evaluation of active and passive seismic earth pressures considering internal friction and cohesion. Soil Dynamics and Earthquake Engineering, 70: 30-47.

Yang, X.L. 2007. Upper bound limit analysis of active earth pressure with different fracture surface and nonlinear yield criterion. Theoretical and Applied Fracture Mechanics, 47(1): 46-56. 


\section{List of Figures}

Fig. 1 Diagram of passive pressure conditions with seepage flow

Fig. 2 Free-body diagram showing forces acting on the retaining wall

Fig. 3 Flowchart of the trial and error procedure for identifying the passive thrust

Fig. 4 Transformation between Cartesian and polar coordinate systems

Fig. 5 Calculation of the weight of the failure wedge

Fig. 6 Schematic diagram of the Kötter equation

Fig. 7 Effects of $\varphi^{\prime}$ on $K_{\mathrm{p}}$ for different $\xi$ values

Fig. 8 Effects of $\varphi^{\prime}$ on $K_{\mathrm{p}}$ for different $\delta$ values

Fig. 9 Effects of $\varphi^{\prime}$ on $K_{\mathrm{p}}$ for different $\xi$ and $\delta$ values

Fig. 10 Free body diagram illustrating the simplified failure mechanism

Fig. 11 Comparison between $K_{\mathrm{p}}$ values with planar and curved failure surface

Fig. A1 Effects of seepage force on $p^{\prime}$ for different $R$ values 


\section{Appendix A}

\section{A1. Solution for cases of saturated soil without seepage flow}

Based on the boundary condition $p^{\prime}=0$ with $\theta=\theta_{m}$ at the tail end portion of the failure surface, Patki et al. (2017) obtained a solution to the original Kötter equation (Eq. 17) for the cases with dry sand.

For the special case of saturated soil without seepage flow inside the backfill, i.e. $\frac{\partial h}{\partial \alpha}=\frac{\partial h}{\partial R}=0$, the modified Kötter equation (Eq. 23) can be reduced to

$$
\frac{\partial p^{\prime}}{\partial \alpha}+2 p^{\prime} \tan \varphi^{\prime}-\gamma^{\prime} R \sin \left(\alpha+\varphi^{\prime}\right)=0
$$

which has the same form as the original Kötter equation but adopts the effective stress parameter (e.g. $p^{\prime}$ and $\left.\varphi^{\prime}\right)$.

By adopting the similar procedure as Patki et al. (2017), the effective soil reactive pressure $p^{\prime}$ along the log-spiral failure surface considering the effect of seepage flow can be obtained as

$$
\begin{aligned}
p^{\prime} & =\frac{r_{0} \gamma^{\prime} \sec \varphi^{\prime}}{1+9 \tan ^{2} \varphi^{\prime}} \mathrm{e}^{\theta \tan \varphi^{\prime}}\left[3 \tan \varphi^{\prime} \sin \left(\theta+\theta_{\mathrm{v}}\right)-\cos \left(\theta+\theta_{\mathrm{v}}\right)\right] \\
& -\frac{r_{0} \gamma^{\prime} \sec \varphi^{\prime}}{1+9 \tan ^{2} \varphi^{\prime}} \mathrm{e}^{\left(3 \theta_{\mathrm{m}}-2 \theta\right) \tan \varphi^{\prime}}\left[3 \tan \varphi^{\prime} \sin \left(\theta_{\mathrm{m}}+\theta_{\mathrm{v}}\right)-\cos \left(\theta_{\mathrm{m}}+\theta_{\mathrm{v}}\right)\right]
\end{aligned}
$$

\section{A2. Solution for the case with planar failure surface}

In a polar coordinate system with $x=R \cdot \sin \alpha$ and $y=H-R \cdot \cos \alpha$, the total head $h$ can be expressed as

$$
h(R, \alpha)=H\left[1-\sum_{m=0}^{\infty} \frac{2}{M^{2}} \mathrm{e}^{-\frac{M \xi R \sin \alpha}{H}} \cos M\left(1-\frac{R}{H} \cos \alpha\right)\right]
$$

and its derivatives are given by

$$
\left\{\begin{array}{l}
\frac{\partial h}{\partial \alpha}=H \sum_{m=0}^{\infty} \frac{2}{M^{2}} \mathrm{e}^{-\frac{M \xi R \sin \alpha}{H}} \frac{M R}{H}\left[\xi \cos \alpha \cos M\left(1-\frac{R}{H} \cos \alpha\right)+\sin \alpha \sin M\left(1-\frac{R}{H} \cos \alpha\right)\right] \\
\frac{\partial h}{\partial R}=H \sum_{m=0}^{\infty} \frac{2}{M^{2}} \mathrm{e}^{-\frac{M \xi R \sin \alpha}{H}} \frac{M}{H}\left[\xi \sin \alpha \cos M\left(1-\frac{R}{H} \cos \alpha\right)-\cos \alpha \sin M\left(1-\frac{R}{H} \cos \alpha\right)\right]
\end{array}\right.
$$


Substituting Eq. (A4) into Eq. (23) yields:

$$
\begin{array}{rl}
I & @ \frac{\partial h}{\partial \alpha} \cos \varphi^{\prime}-\frac{\partial h}{\partial R} R \sin \varphi^{\prime} \\
=H \sum_{m=0}^{\infty} \frac{2 R}{M H} \mathrm{e}^{-\frac{M \xi R \sin \alpha}{H}}\left[\xi \cos M\left(1-\frac{R}{H} \cos \alpha\right) \cos (\alpha+\varphi)+\sin M\left(1-\frac{R}{H} \cos \alpha\right) \sin (\alpha+\varphi)\right]
\end{array}
$$

When the seepage flow is isotropic ( $\xi=1.0)$, Eqs. (A4) and (A5) can be reduced to

$$
\left\{\begin{array}{l}
\frac{\partial h}{\partial \alpha}=H \sum_{m=0}^{\infty} \frac{2}{M^{2}} \mathrm{e}^{-\frac{M R \sin \alpha}{H}} \frac{M R}{H} \cos \left[\alpha-M\left(1-\frac{R}{H} \cos \alpha\right)\right] \\
\frac{\partial h}{\partial R}=H \sum_{m=0}^{\infty} \frac{2}{M^{2}} \mathrm{e}^{-\frac{M R \sin \alpha}{H}} \frac{M}{H} \sin \left[\alpha-M\left(1-\frac{R}{H} \cos \alpha\right)\right]
\end{array}\right.
$$

and

$$
I=H \sum_{m=0}^{\infty} \frac{2 R}{M H} \mathrm{e}^{-\frac{M R \sin \alpha}{H}} \cos \left[\alpha-M\left(1-\frac{R}{H} \cos \alpha\right)+\varphi\right]
$$

Fig. A1 shows the relationship between the dimensionless term $|I|_{\max } / H=\sum_{m=0}^{\infty} \frac{4 R}{M H} \mathrm{e}^{-\frac{M \xi R \sin \alpha}{H}}$ and the curvature radius $R\left(\alpha=40^{\circ}\right)$, where $|I|_{\max }$ is the maximum of $I$. It is seen that the seepage term $|/|_{\max } / H$ increases with $R / H$ first, then peaks when $R / H<5$ before falling to zero when $R / H$ further increases. This suggests that the seepage effect is negligible when $R / H$ is large, under both isotropic and anisotropic seepage conditions. Nevertheless, the effect of seepage force becomes more significant when $R / H$ is small, especially under more anisotropic seepage flow conditions (smaller $\xi$ values).

For the case with planer failure surface under passive state, the curvature radius $R=\frac{\partial s}{\partial \alpha} \rightarrow \infty$, and thus the modified Kötter equation is approximately the same as Eq. (A1). For the planar failure surface shown in Fig. 10, Eq. (A1) can be expressed as

$$
\frac{\partial p^{\prime}}{\partial s}=\gamma^{\prime} \sin \left(\alpha+\varphi^{\prime}\right)
$$

By applying the boundary condition $p^{\prime}=0$ at the point $F$ and $\alpha=\varepsilon$ along the failure 
surface, where $\varepsilon$ is the angle between the planar failure surface and the horizontal direction (Fig. 10), the solution to Eq. (A8) can be written as,

$$
p^{\prime}=\gamma^{\prime} \sin \left(\varepsilon+\varphi^{\prime}\right) s
$$

where $s$ is the distance of a point measured from the point $F$. Therefore, the stress at point $D$ can be obtained as

$$
p_{\mathrm{D}}{ }^{\prime}=\gamma^{\prime} H \sin \left(\varepsilon+\varphi^{\prime}\right) \csc \varepsilon
$$

Integration of Eq. (A9) yields the effective resultant soil reaction $R_{\mathrm{s}}{ }^{\prime}$ acting on the planar failure surface DF, as follows:

$$
R_{\mathrm{s}}^{\prime}=\gamma^{\prime} \sin \left(\varepsilon+\varphi^{\prime}\right) \frac{(H \csc \varepsilon)^{2}}{2}
$$




\section{List of Tables}

Table 1 Comparison of proposed $P_{\mathrm{p}}$ values with Shield and Tolunay (1973)

Table 2 Comparison of proposed $K_{\mathrm{p}}$ values with other theoretical results 
Table 1. Comparison of proposed $P_{p}$ values with Shield and Tolunay (1973)

\begin{tabular}{|c|c|c|c|c|c|c|c|c|c|c|}
\hline \multirow{2}{*}{$\varphi^{\prime}\left({ }^{\circ}\right)$} & \multicolumn{5}{|c|}{ Proposed method } & \multicolumn{5}{|c|}{ Shield and Tolunay (1973) } \\
\hline & $P_{\mathrm{p}}(\mathrm{kN})$ & $P_{\mathrm{h}}(\mathrm{kN})^{*}$ & $P_{\mathrm{v}}(\mathrm{kN})^{*}$ & $P_{\mathrm{p}}{ }^{\mathrm{h}}(\mathrm{kN})^{* *}$ & $P_{\mathrm{p}}{ }^{\mathrm{v}}(\mathrm{kN})^{* *}$ & $P_{\mathrm{p}}(\mathrm{kN})$ & $P_{\mathrm{h}}(\mathrm{kN})$ & $P_{\mathrm{v}}(\mathrm{kN})$ & $P_{\mathrm{p}}{ }^{\mathrm{h}}(\mathrm{kN})$ & $P_{\mathrm{p}}^{\mathrm{v}}(\mathrm{kN})$ \\
\hline 20 & 554.025 & 545.61 & 96.21 & 554.025 & 554.025 & 522.80 & 480.33 & -206.43 & 390.25 & -951.00 \\
\hline 25 & 696.8 & 680.28 & 150.82 & 696.8 & 696.8 & 656.79 & 623.20 & -207.35 & 510.75 & -766.50 \\
\hline 30 & 891.125 & 860.76 & 230.64 & 891.125 & 891.125 & 850.23 & 827.05 & -197.20 & 685.00 & -609.50 \\
\hline 35 & 1192.05 & 1136.88 & 358.46 & 1192.05 & 1192.05 & 1142.28 & 1130.25 & -165.38 & 948.00 & -440.00 \\
\hline 40 & 1650.5 & 1550.96 & 564.50 & 1650.5 & 1650.5 & 1607.55 & 1605.33 & -84.63 & 1366.75 & -209.75 \\
\hline 45 & 2393.55 & 2211.35 & 915.97 & 2393.55 & 2393.55 & 2327.42 & 2326.03 & 80.70 & 2079.00 & 168.75 \\
\hline
\end{tabular}


Table 2. Comparison of proposed $K_{\mathrm{p}}$ values with other theoretical results

\begin{tabular}{|c|c|c|c|c|c|c|c|c|}
\hline$\varphi^{\prime}\left({ }^{\circ}\right)$ & $\delta / \varphi^{\prime}$ & $\begin{array}{c}\text { Proposed } \\
\text { method }\end{array}$ & $\begin{array}{c}\text { Patki et al. } \\
\text { (2017) }\end{array}$ & $\begin{array}{l}\text { Soubra } \\
(2000)\end{array}$ & $\begin{array}{l}\text { Lancellotta } \\
\text { (2002) }\end{array}$ & $\begin{array}{l}\text { Shiau } \\
\text { et al. } \\
(2008)\end{array}$ & $\begin{array}{l}\text { Antão } \\
\text { et al. } \\
\text { (2011) }\end{array}$ & $\begin{array}{l}\text { Patki et al. } \\
\text { (2015b) }\end{array}$ \\
\hline \multirow[t]{4}{*}{20} & $1 / 3$ & 2.09 & 2.39 & 2.39 & 2.37 & 2.42 & 2.39 & 2.86 \\
\hline & $1 / 2$ & 2.22 & 2.57 & 2.58 & 2.52 & 2.62 & 2.56 & 3.01 \\
\hline & $2 / 3$ & 2.39 & 2.75 & 2.77 & 2.65 & 2.82 & 2.73 & 3.17 \\
\hline & 1 & 2.55 & 3.13 & 3.12 & 2.87 & 3.21 & 3.05 & 3.51 \\
\hline \multirow[t]{4}{*}{25} & $1 / 3$ & 2.54 & 3.07 & 3.08 & 3.03 & 3.11 & 3.07 & 3.64 \\
\hline & $1 / 2$ & 2.79 & 3.41 & 3.43 & 3.30 & 3.48 & 3.39 & 3.95 \\
\hline & $2 / 3$ & 3.11 & 3.76 & 3.79 & 3.56 & 3.86 & 3.72 & 4.26 \\
\hline & 1 & 3.43 & 4.54 & 4.51 & 4.00 & 4.70 & 4.36 & 5.03 \\
\hline \multirow[t]{4}{*}{30} & $1 / 3$ & 3.16 & 4.03 & 4.05 & 3.95 & 4.10 & 4.02 & 4.72 \\
\hline & $1 / 2$ & 3.56 & 4.65 & 4.69 & 4.44 & 4.76 & 4.62 & 5.31 \\
\hline & $2 / 3$ & 4.19 & 5.34 & 5.40 & 4.93 & 5.49 & 5.25 & 5.94 \\
\hline & 1 & 4.98 & 6.93 & 6.86 & 5.80 & 7.14 & 6.56 & 7.59 \\
\hline \multirow[t]{4}{*}{35} & $1 / 3$ & 4.06 & 5.44 & 5.48 & 5.28 & 5.58 & 5.42 & 6.27 \\
\hline & $1 / 2$ & 4.77 & 6.59 & 6.67 & 6.16 & 6.77 & 6.52 & 7.38 \\
\hline & $2 / 3$ & 5.53 & 7.95 & 8.06 & 7.09 & 8.17 & 7.76 & 8.64 \\
\hline & 1 & 8.10 & 11.31 & 11.13 & 8.85 & 11.50 & 10.58 & 12.23 \\
\hline \multirow[t]{4}{*}{40} & $1 / 3$ & 5.39 & 7.62 & 7.70 & 7.28 & 7.79 & 7.57 & 8.62 \\
\hline & $1 / 2$ & 6.60 & 9.81 & 9.99 & 8.92 & 10.03 & 9.67 & 10.75 \\
\hline & $2 / 3$ & 8.44 & 12.58 & 12.93 & 10.71 & 12.87 & 12.19 & 13.30 \\
\hline & 1 & 13.00 & 20.01 & 19.62 & 14.39 & 20.10 & 18.15 & 21.49 \\
\hline \multirow[t]{4}{*}{45} & $1 / 3$ & 7.41 & 11.18 & 11.36 & 10.48 & 11.41 & 11.09 & 12.38 \\
\hline & $1 / 2$ & 9.57 & 15.61 & 15.98 & 13.60 & 15.85 & 15.29 & 16.59 \\
\hline & $2 / 3$ & 13.22 & 21.78 & 22.22 & 17.27 & 22.03 & 20.75 & 22.09 \\
\hline & 1 & 23.50 & 39.91 & 38.61 & 25.47 & 45.14 & 34.99 & 42.40 \\
\hline
\end{tabular}




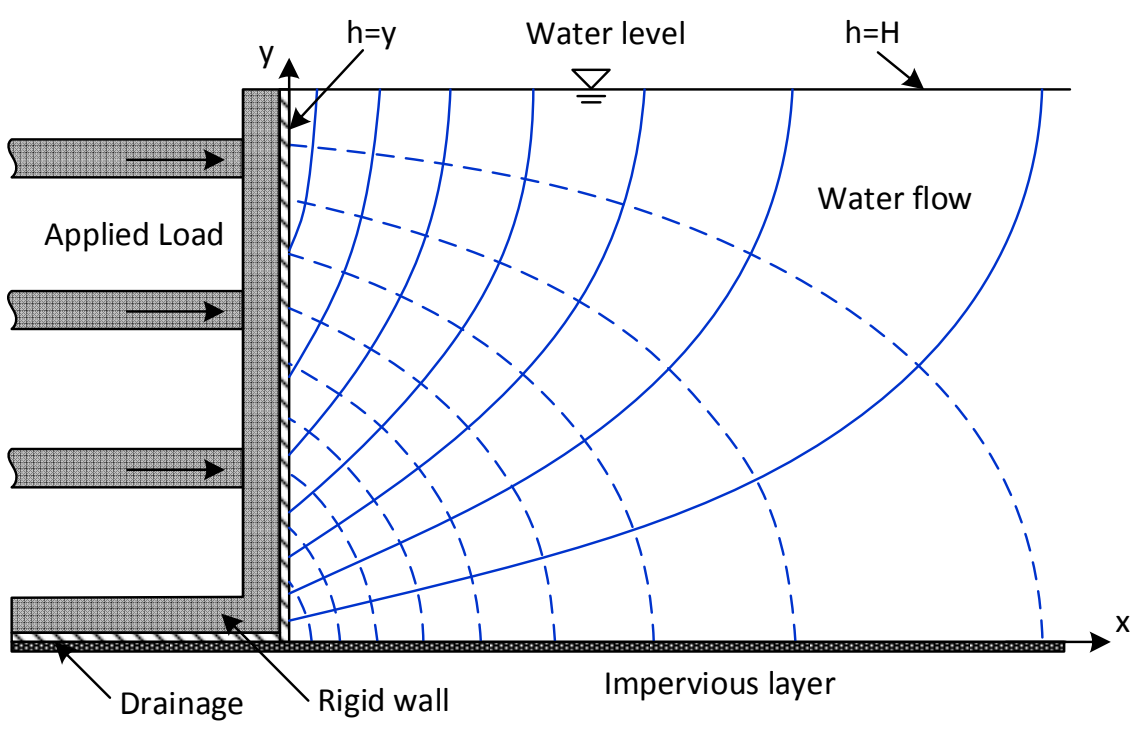

Fig. 1. Diagram of passive pressure conditions with seepage flow 
0

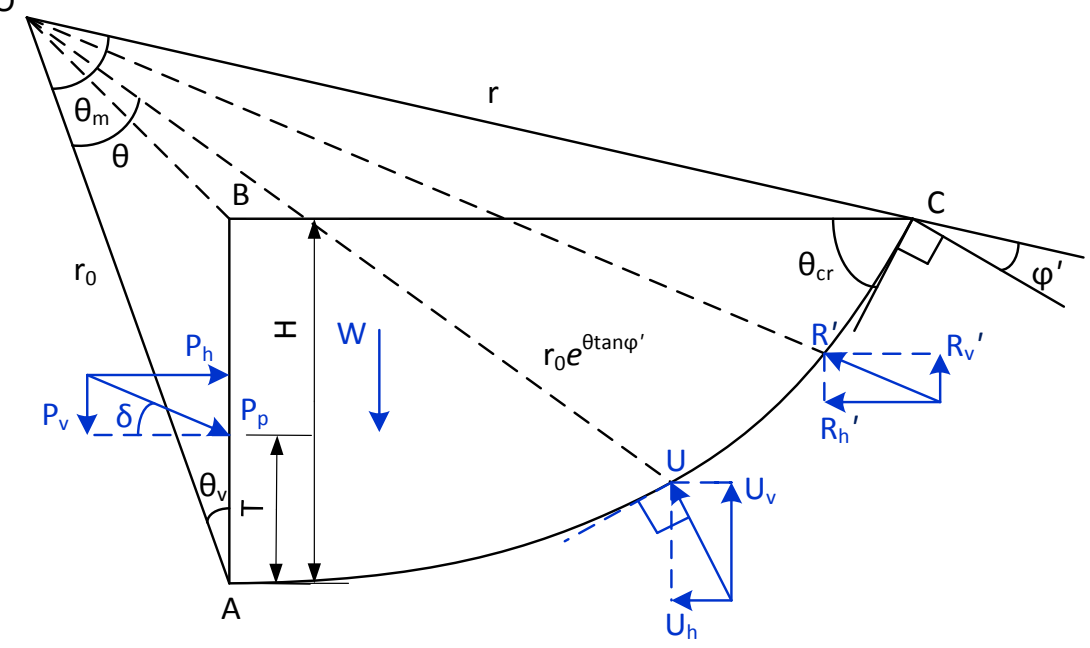

Fig. 2. Free-body diagram showing forces acting on the retaining wall 


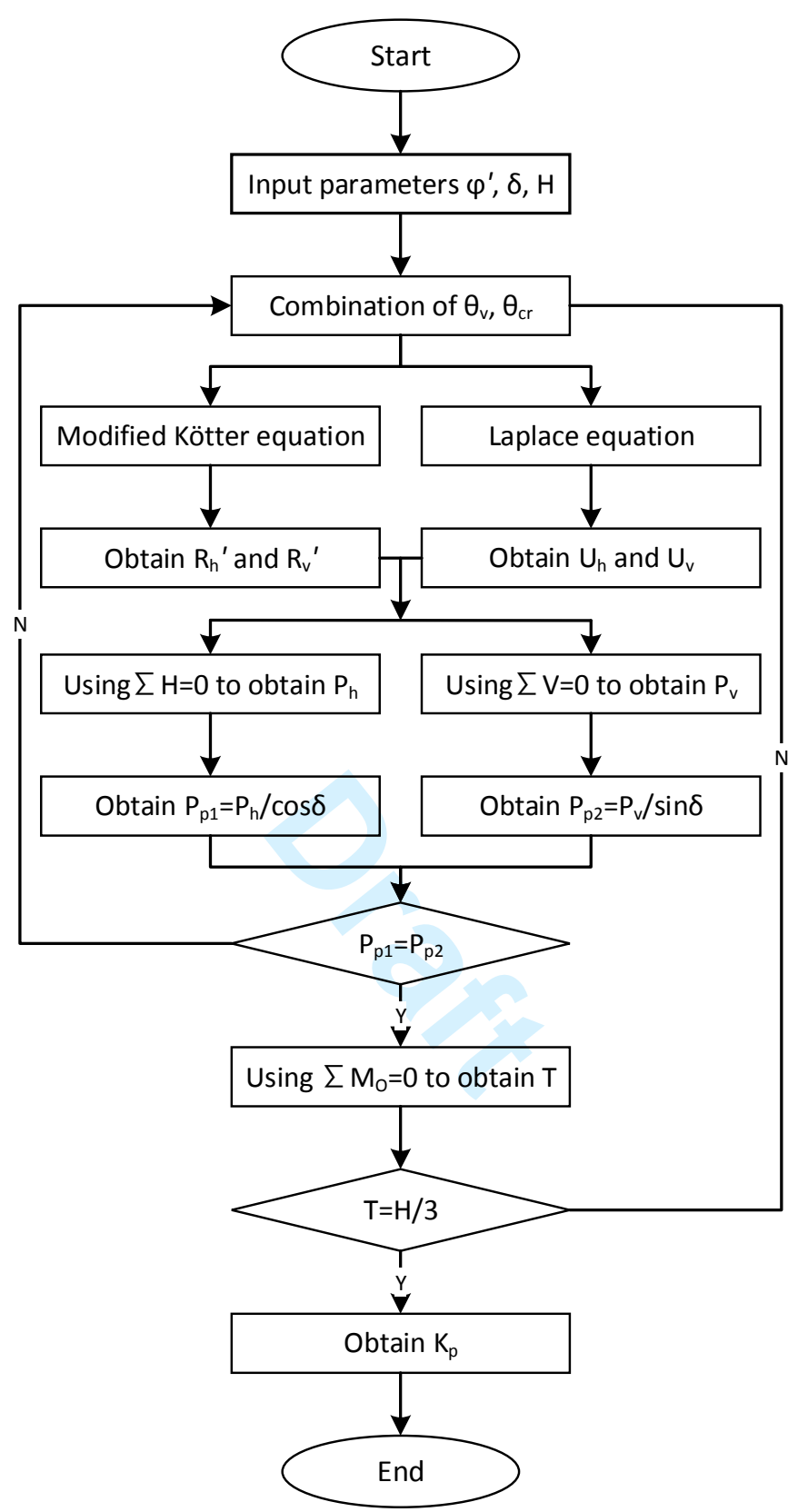

Fig. 3. Flowchart of the trial and error procedure for identifying the passive thrust 


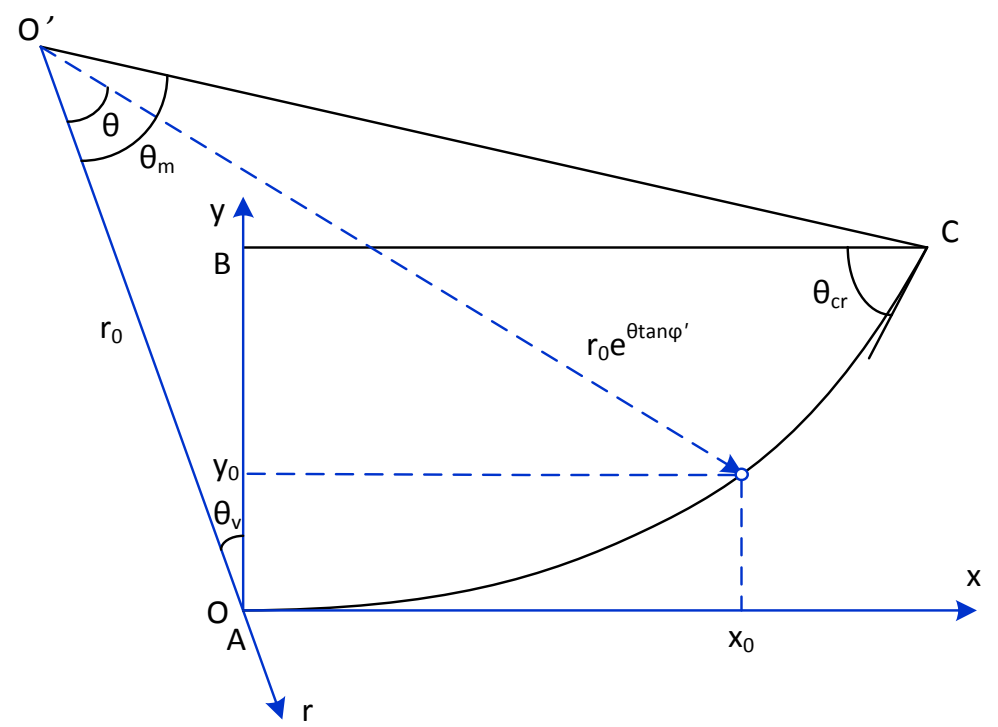

Fig. 4. Transformation between Cartesian and polar coordinate systems 


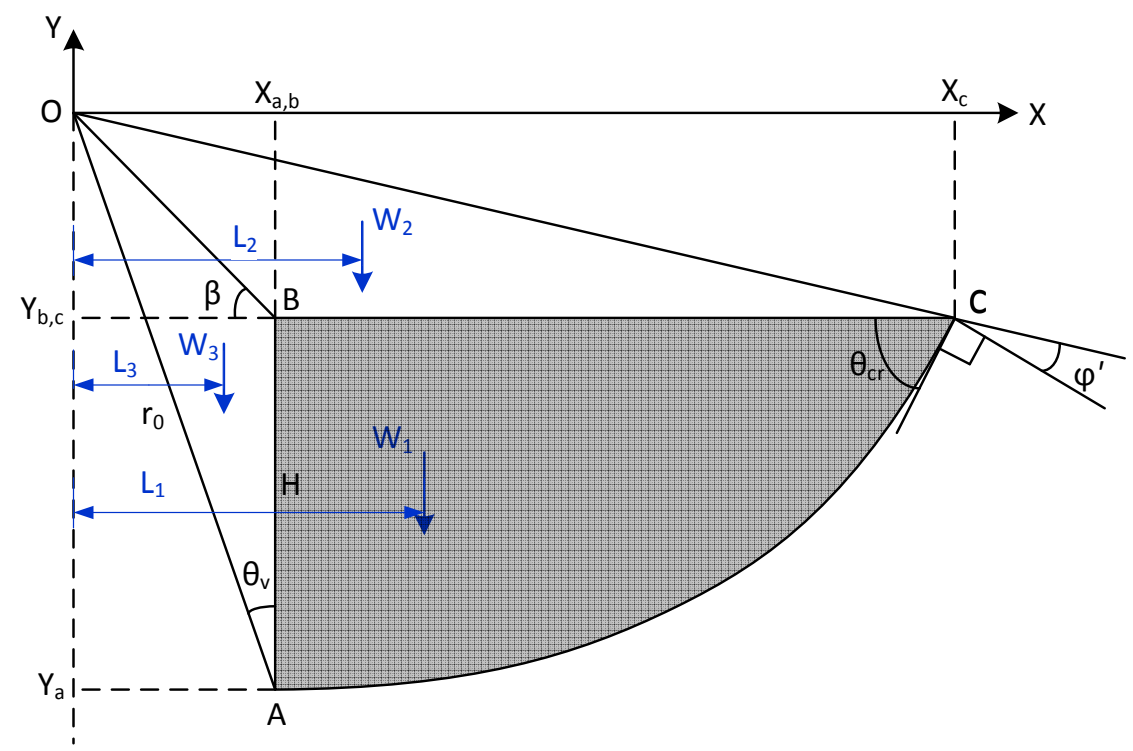

Fig. 5. Calculation of the weight of the failure wedge 


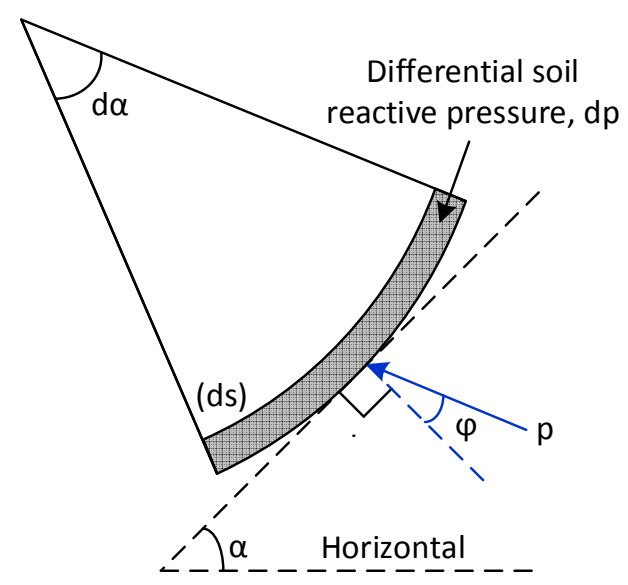

Fig. 6. Schematic diagram of the Kötter equation 


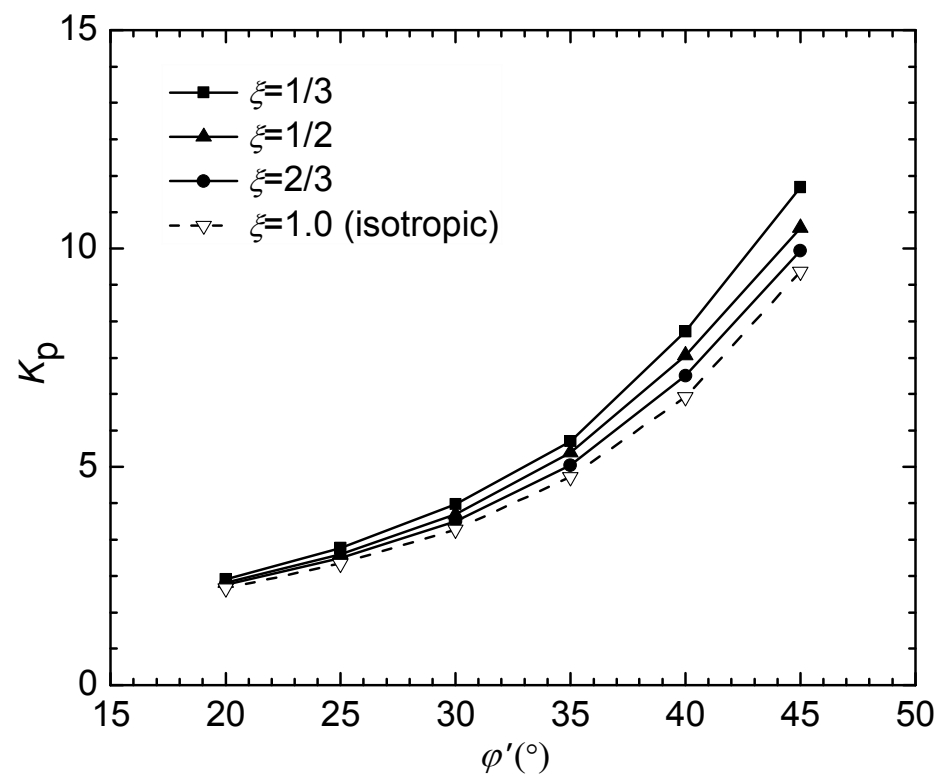

Fig. 7. Effects of $\varphi^{\prime}$ on $K_{\mathrm{p}}$ for different $\xi$ values 


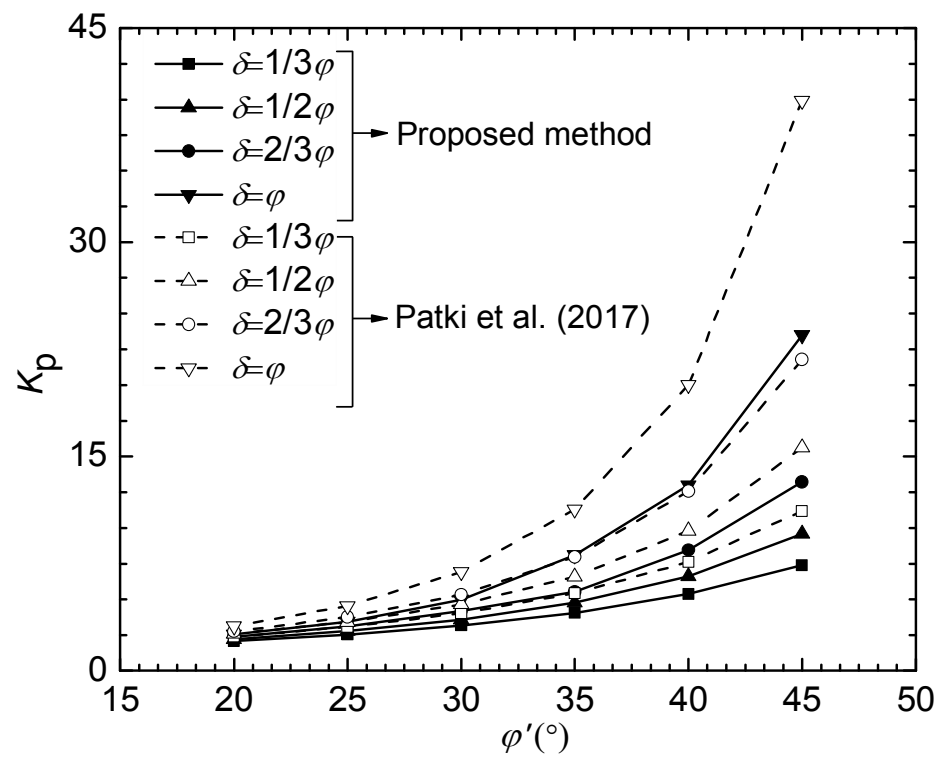

Fig. 8. Effects of $\varphi^{\prime}$ on $K_{\mathrm{p}}$ for different $\delta$ values 


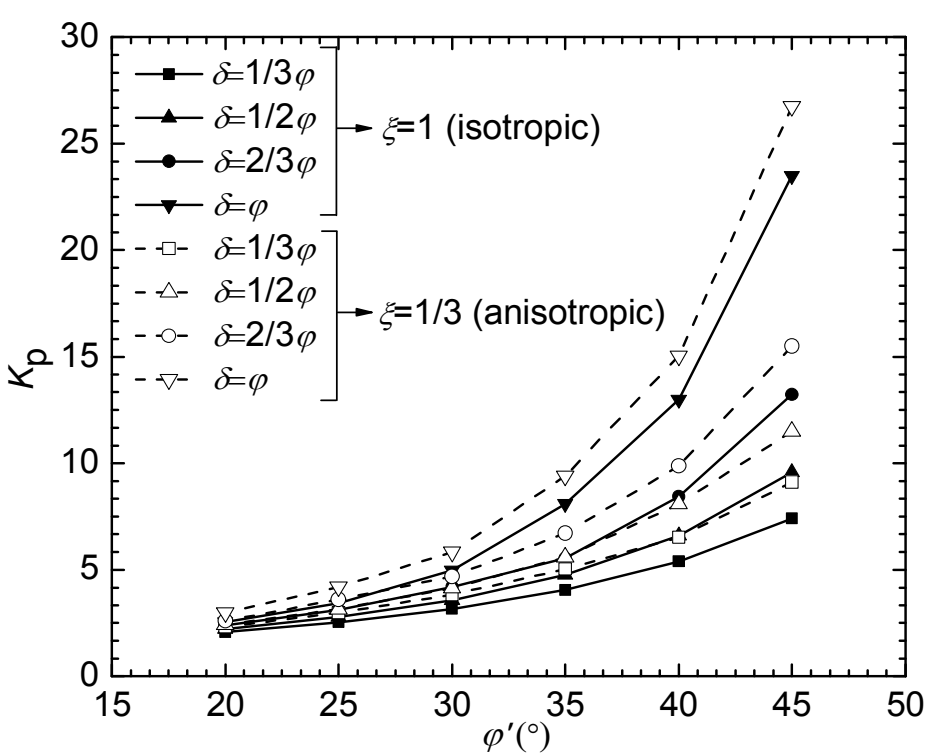

Fig. 9. Effects of $\varphi^{\prime}$ on $K_{\mathrm{p}}$ for different $\xi$ and $\delta$ values 


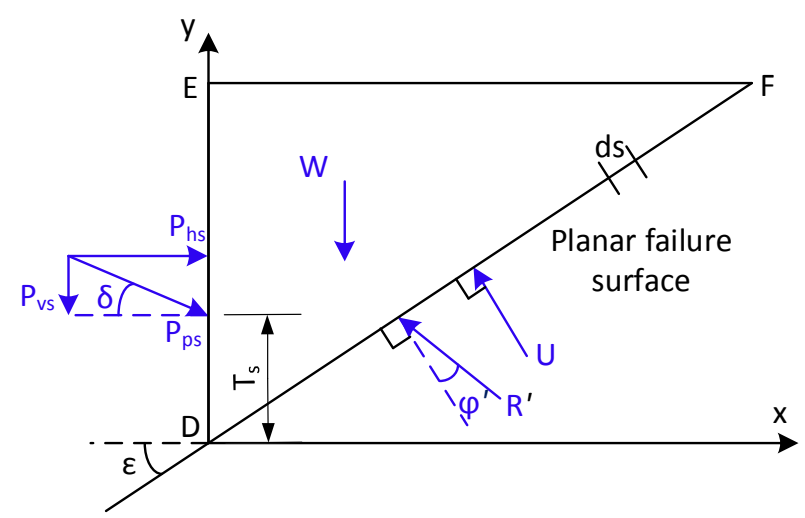

Fig. 10. Free body diagram illustrating the simplified failure mechanism 


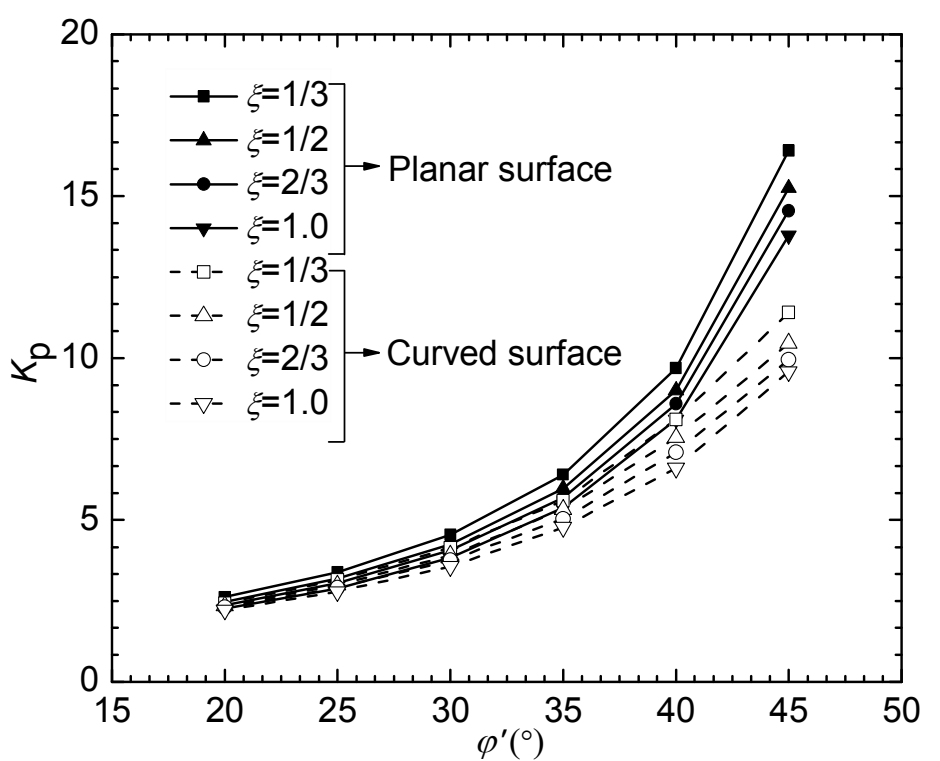

Fig. 11. Comparison between $K_{\mathrm{p}}$ values with planar and curved failure surface 


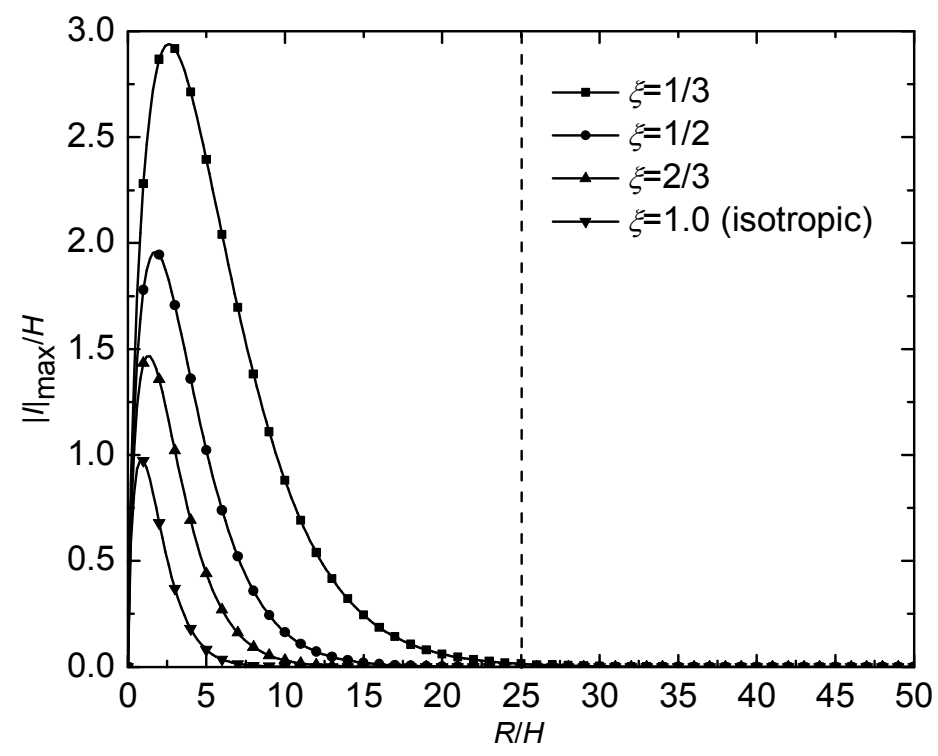

Fig. A1. Effects of seepage force on $p^{\prime}$ for different $R$ values 